Check for updates

Cite this: Mater. Adv., 2020 1,554

Received 10th April 2020 Accepted 8th May 2020

DOI: 10.1039/d0ma00191k

rsc.li/materials-advances

\section{The stability of a graphene oxide (GO) nanofiltration (NF) membrane in an aqueous environment: progress and challenges}

\author{
Zhenxing Wang, (D)*a Fang He, ${ }^{a}$ Jing Guo, ${ }^{b}$ Shaogin Peng, ${ }^{a}$ Xi Quan Cheng, ${ }^{c}$ \\ Yingjie Zhang, ${ }^{c}$ Enrico Drioli, (D) ${ }^{d}$ Alberto Figoli, ${ }^{d}$ Yuexiang Li (D) ${ }^{* a}$ and Lu Shao (D) ${ }^{b}$
}

\begin{abstract}
Recently, advanced membranes based on a 2D material of graphene oxide (GO) for NF have drawn great attention due to their striking, dramatic separation performances which are much higher than traditional membranes. However, stability, which is a precondition for practical applications, has become the bottleneck of the GO membranes for water treatment. Fortunately, the stability of GO membranes in water has received significant attention, and many fruitful efforts have been recently devoted to solving this problem. It is therefore critical to update the broader scientific community on the important advances in this interdisciplinary field. Herein, we review the recent progress made in improving the stability of GO membranes in water. Fundamental issues, including the origin of the instability of GO membranes in water, and influences of the chemical properties of GO itself on the stability of the resultant membranes have been discussed. We also explore the diverse structural design and surface/ interface engineering strategies for improving the stability of GO membranes in water, including the introduction of hydrogen bonding or intermolecular interactions via insertion of polyelectrolytes, crosslinking by molecules or ions, or blending of graphene-based materials, as well as improving the interactions between GO selective layers and substrates. The existing challenges and a forward-looking perspective are also outlined, suggesting directions to take in the design of GO and other 2D materialbased membranes with outstanding stability and high separation performance for practical applications.
\end{abstract}

${ }^{a}$ Department of Chemistry, Nanchang University, Nanchang 330031, P. R. China.E-mail:wzx_1009@163.com, liyx@ncu.edu.cn

${ }^{b}$ MIIT Key Laboratory of Critical Materials Technology for New Energy Conversion and Storage, State Key Laboratory of Urban Water Resource and Environment, School of Chemistry and Chemical Engineering, Harbin Institute of Technology, Harbin 150001, P. R. China. E-mail: shaolu@hit.edu.cn

${ }^{c}$ School of Marine Science and Technology, Sino-Europe Membrane Technology Research Institute, Harbin Institute of Technology, Weihai 264209, P. R. China

${ }^{d}$ Institute on Membrane Technology (ITM-CNR), Via P. Bucci 17c, 87036 Rende (CS), Italy

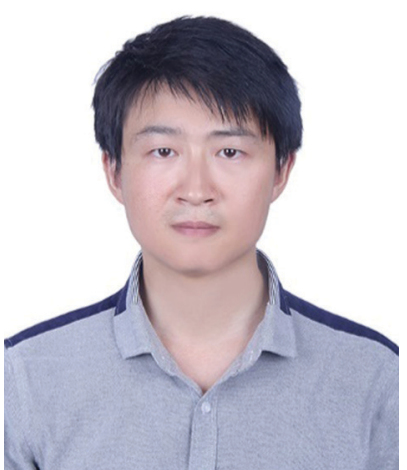

Zhenxing Wang
Zhenxing Wang received his $P h D$ degree from Harbin Institute of Technology in 2017. His research focuses on mussel-inspired surface engineering for water-remediation materials such as superwetting materials for oil/water separation, functional membranes for wastewater treatment, and photothermal materials for clean water generation.

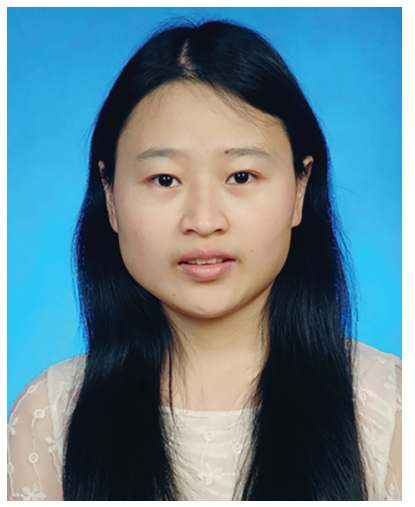

Fang He
Fang $\mathrm{He}$ received her $M S$ in Inorganic Chemistry in 2011 from Nanchang University and her PhD in Chemical Engineering and Technology in 2017 from Harbin Institute of Technology. She visited the group of Prof. Bin Liu at Nanyang Technological University as an exchange student during 2015.09-2016.09. At present, she is a Lecturer in the Department of Chemistry, Nanchang University. Her current research interests concentrate on the design and synthesis of photocatalytic/photothermal materials for energy and environmental applications. 


\section{Introduction}

A nanofiltration (NF) membrane is a barrier with well-defined nano-size pores and surface properties which can realize the selective transmission of solute with a low molecular weight and low valence ions while blocking other species. ${ }^{1-4} \mathrm{NF}$ membranes have been widely used for wastewater treatment, pure water production, and other industrial productions. ${ }^{3-9}$ An ideal NF membrane for water treatment should have high water flux while maintaining the required rejection rate under a relatively low pressure. As according to the classical hydrodynamics theory described by the Hagen-Poiseuille Equation ${ }^{10}$

$$
J=\varepsilon r_{\mathrm{p}}{ }^{2} \Delta p / 8 \mu L
$$

where $J$ is the permeation flux, $\varepsilon$ is the surface porosity, $r_{\mathrm{p}}$ is the effective pore radius, $\Delta p$ is the hydraulic pressure difference, $\mu$ is the liquid viscosity, and $L$ is the membrane thickness. According to the equation, to obtain high permeation flux, the selective layer of an NF membrane should be as thin as possible. Moreover, to realize the effective rejection of certain small organic

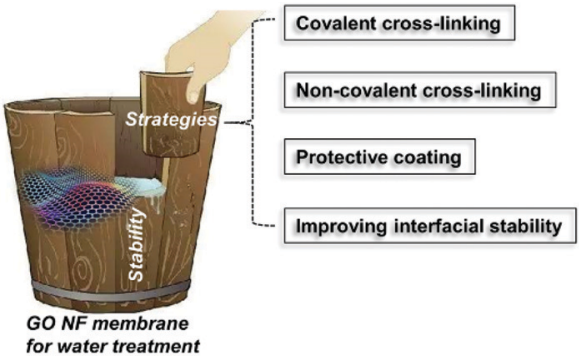

Scheme 1 The strategies for improving the stability of GO membranes in an aqueous environment.

molecules or high valence ions, the selective layer should have precisely adjustable nanopores or channels.

Recently, 2D materials of graphene oxide (GO) have drawn great attention due to their great advantages for the preparation of advanced NF membranes. ${ }^{11-19}$ On the one hand, the monolayer GO nanosheets with a thickness of less than $1 \mathrm{~nm}$ can form an ultrathin selective layer on many substrates via filtration, self-assembly, ${ }^{20,21}$ blade coating, spraying, spin coating, printing, and shear alignment. ${ }^{22}$ On the other hand, the nanochannels in

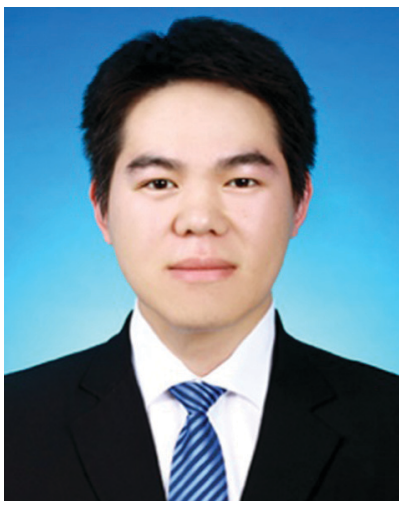

Jing Guo
Jing Guo received his bachelor degree (2015) and master degree (2017) from Harbin Institute of Technology, China. He is now a PhD candidate in School of Chemical Engineering and Technology at Harbin Institute of Technology (HIT) under professor Lu Shao. His current research focuses on advanced membranes fabricated by $2 D$ materials and their applications for water purification and organic solvent nanofiltration.

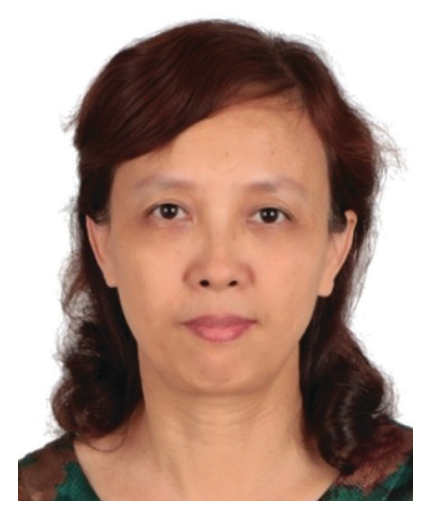

Shaoqin Peng received her bachelor degree (1985), master degree (1999), and doctor degree (2005) from Nanchang University, China. She is currently a full professor at the College of Chemistry, Nanchang University, China. Her research interests cover photocatalytic and micro-nano materials for energy conversion.

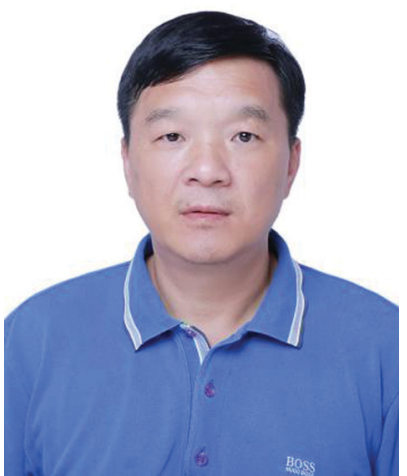

Yuexiang $\mathbf{L i}$
Yuexiang $L i$ received his $P h D$ degree from Lanzhou Institute of Chemical Physics, the Chinese Academy of Sciences; in 2002. He is now a Professor at the College of Chemistry, Nanchang University. His current research interests focus on semiconductor photocatalysis, electrocatalysis and photoelectrocatalysis for water splitting, nano-materials and interface-materials.

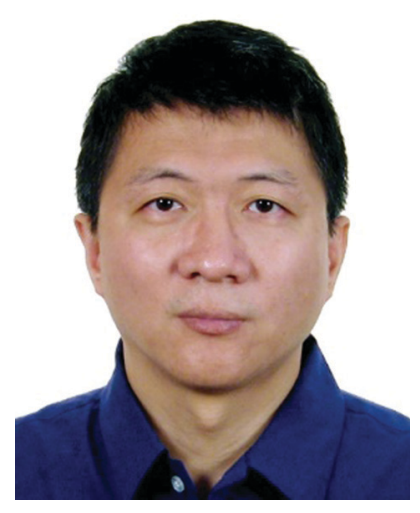

Lu Shao
Lu Shao, is currently a full professor at the School of Chemical Engineering and Technology at Harbin Institute of Technology (HIT) in China. He received his BSC (1999) and MSc (2001) from HIT, and his PhD (2005) from the National University of Singapore. Before joining HIT in 2006, he had worked as the assistant project manager in C-PAK Company, Singapore for more than one year. His research interests are advanced separation membrane materials and functional composite materials, with a particular focus on energy and environmental applications. 
A

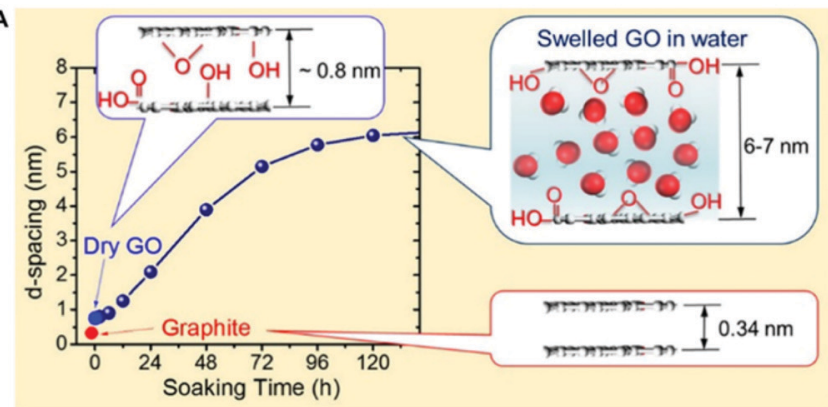

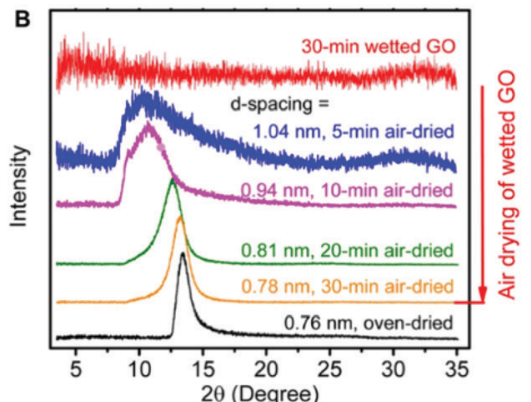

Fig. 1 (A) Schematic illustration of $d$-spacings of graphite, dry GO, and GO soaked in water. ${ }^{35}$ (B) XRD spectra of a GO membrane in oven-dried, wetted, and air-dried conditions. ${ }^{35}$ (A) and (B) were reprinted with permission from ref. 35.

the GO selective layer can be precisely modulated by adjusting the interlayer spacing between the GO layers. ${ }^{23-27}$ The nanochannels in the ultrathin selective layer, as well as the nanopores on the GO sheets, can endow the GO-based NF membrane with ultrahigh water permeation flux that is orders of magnitude higher than that of traditional polymer-based NF membranes. ${ }^{28-31}$ The precisely adjustable nanochannels of the GO-based selective layer can realize precise molecular sieving as needed. ${ }^{30,32-34}$

To date, a series of GO NF membranes with excellent performances has been prepared via various ingenious strategies, and scaling-up of these membranes to large-areas has also been overcome ${ }^{22}$ which suggest that the industrial application prospects of GO NF are increasing. However, as far as we know, the

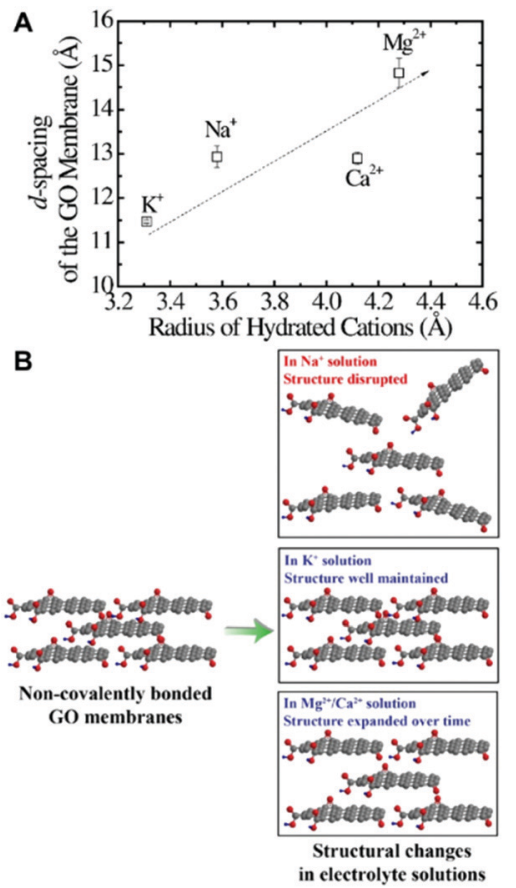

Fig. 2 The cation-dependent laminar structure of GO membranes. (A) Impact of the hydrated radius of cations on the $d$-spacing of the GO membrane directly after immersion. ${ }^{39}$ (B) The GO membrane structure after long exposure to electrolyte solutions. ${ }^{39}(A)$ and (B) were reprinted with permission from ref. 39 . application of GO NF membranes remains still at the laboratory or pilot-plant scale, without industrialization. One of the biggest stumbling blocks is the instability of GO membranes in water. Without long-term stability in water, the industrial application of GO membranes is merely a castle in the air.

Therefore, the stability of GO NF membranes in water has received significant attention recently, and many fruitful efforts

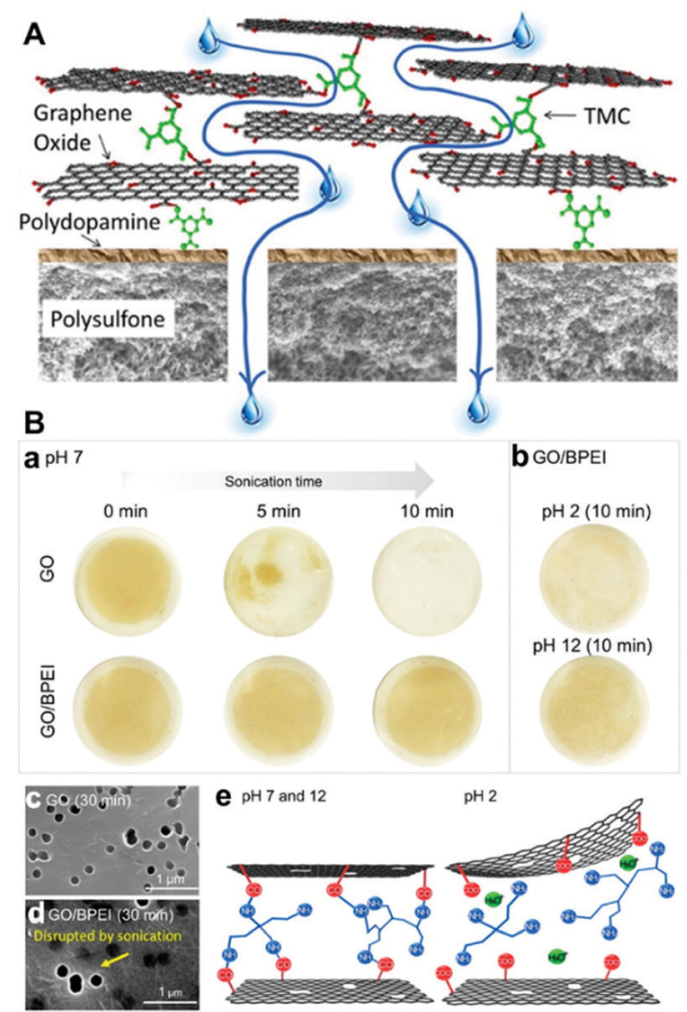

Fig. 3 (A) Schematic illustration of the fabrication of a GO membrane via the layer-by-layer deposition of GO nanosheets, which were cross-linked by 1,3,5-benzenetricarbonyl trichloride, on a polydopamine-coated polysulfone support. ${ }^{48}$ (B) Stability of GO/BPEl membranes in an aqueous solution: (a) stability after sonication treatment, (b) stability in acid-base solutions, (c and d) SEM images of membranes after sonication for $30 \mathrm{~min}$ at $\mathrm{pH}$ 7, (e) mechanism of stabilization of the GO/BPEl membrane at different $\mathrm{pH}$ values. ${ }^{51}(\mathrm{~A})$ and $(\mathrm{B})$ were reprinted with permission from ref. 48 and 51, respectively. 
have been devoted to solving this problem. It is therefore critical to update the broader scientific community on the important advances in this interdisciplinary field.

Herein, we review the recent progress made in improving the stability of GO membranes in water (Scheme 1). Fundamental issues, including the origin of the instability of GO membranes in water, and influences of the chemical properties of GO itself on the stability of the resultant membranes have been discussed. We also explore the diverse structural design and surface/interface engineering strategies for improving the stability of GO membranes in water, including the introduction of hydrogen bonding or intermolecular interactions via insertion of polyelectrolytes, cross-linking by molecules or ions, or blending of graphene-based materials, as well as improving the interaction between GO layers and substrates. The existing challenges and a forward-looking perspective are also discussed, suggesting directions to take in the design of GO and other 2D material-based membranes with outstanding stability and high separation performance for practical applications.

\section{The origin of the instability of neat GO membranes in an aqueous environment}

It is well known that there are many hydrophilic oxygenated functional groups in GO sheets, and these highly hydrophilic groups attract water molecules into the interlayer space of the GO membrane, hydrating the GO sheets and increasing the interlayer space (Fig. 1). ${ }^{35,36}$ The hydration as well as the electrostatic repulsion generated by negatively charged oxygen-containing groups leads to the swelling of the GO membrane in water, and the swelling will finally overcome the van der Waals attractions or hydrogen bonding that holds the GO sheets together, leading to the disintegration of the GO membrane. ${ }^{37}$ Note that the high or low $\mathrm{pH}$ value will increase the electrostatic repulsion of GO sheets, further aggravating the instability of the GO membrane in water. $^{38}$ Moreover, some cations in water can also affect the structural instability of GO membranes. For example, the GO membrane structure can be disrupted by $\mathrm{Na}^{+}$(Fig. 2), ${ }^{39,40}$ while the stability of the GO membrane can be improved by $\mathrm{Al}^{3+} \cdot 37$
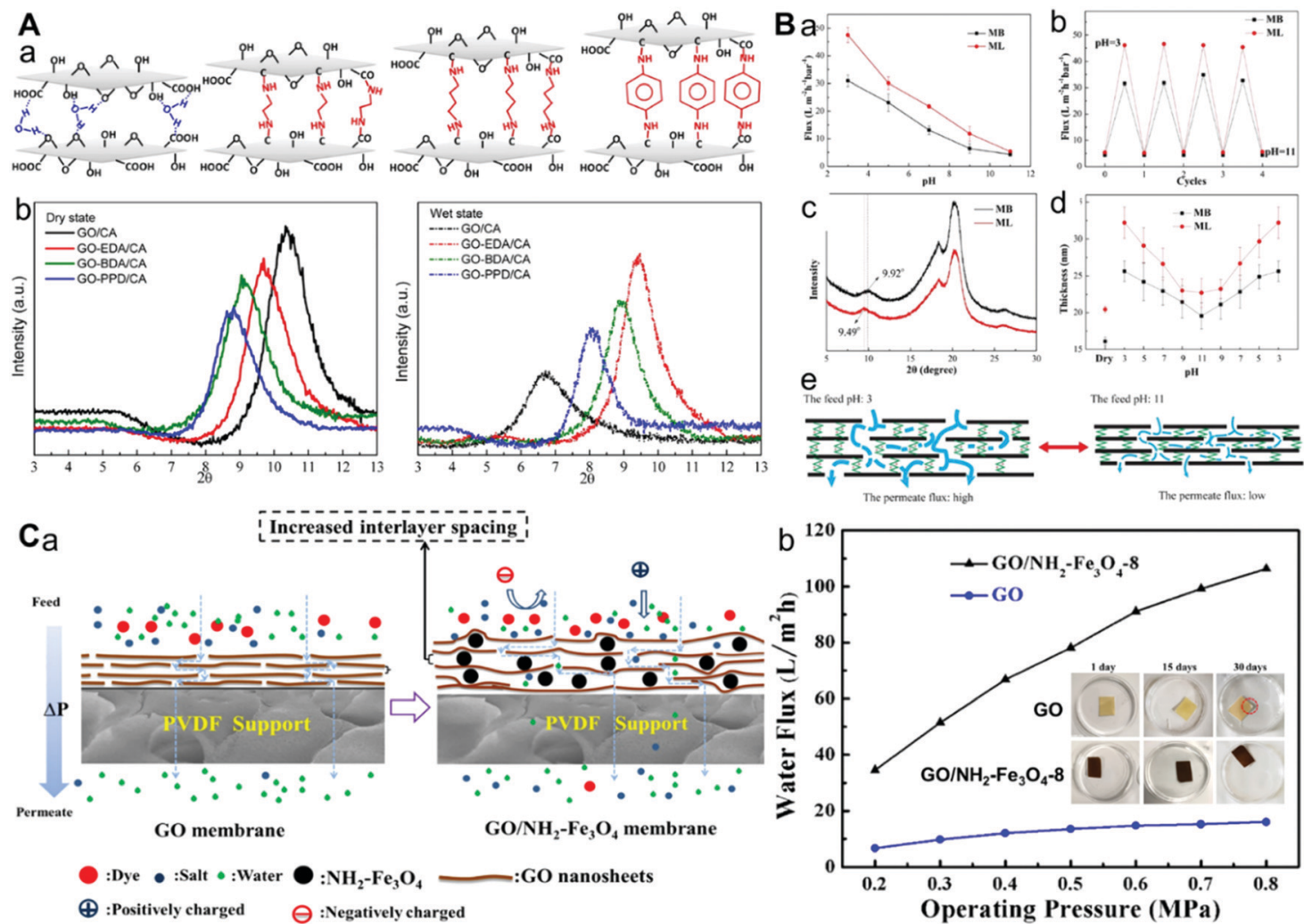

Fig. 4 (A) Cross-linking with diamine monomers to prepare GO membranes with varying amounts of $d$-spacing. ${ }^{49}$ (a) Structural diagram of GO and three composite graphene oxide-framework (GOF) membranes (GO-EDA, GO-BDA, and GO-PPD). Each GOF was produced by cross-linking GO with a diamine monomer (EDA, BDA, or PPD). (b) XRD patterns of GO and GOF membranes in dry and wet states, respectively. (B) pH-Responsive $d$-spacing of graphene-based stable pH-responsive membranes (GPMs). ${ }^{58}$ (a) Permeation flux of the GPM prepared from GO and the linear PEI (denoted as ML) or the branched PEI (denoted as MB) in the $\mathrm{pH}$ range from 3 to 11, respectively, (b) permeation flux of $\mathrm{MB}$ and $\mathrm{ML}$ when the $\mathrm{pH}$ value shifted from 11 to 3 and back to 11 for four cycles, (c) XRD spectra of MB and ML, (d) film thickness of MB and ML at different pH values, and (e) schematic of potential conformation change of GPM at $\mathrm{pH} 3$ and 11. (C) $\mathrm{NH}_{2}-\mathrm{Fe}_{3} \mathrm{O}_{4}$ regulated $\mathrm{GO}$ membrane with well-defined laminar nanochannels; ${ }^{64}$ (a) mechanisms of the transport process of $\mathrm{GO}$ and $\mathrm{GO} / \mathrm{NH}_{2}-\mathrm{Fe}_{3} \mathrm{O}_{4}$ membranes and (b) the effect of operating pressure on water flux of $\mathrm{GO}$ and $\mathrm{GO} / \mathrm{NH}_{2}-\mathrm{Fe}_{3} \mathrm{O}_{4}-8$ membranes. (A-C) were reprinted with permission from ref. 49, 58 and 64 , respectively. 
Another stability problem of the GO membrane is related to the substrates. The mechanical strength of a thin GO membrane is not good enough for application, so porous substrates are usually needed to support the GO membrane. ${ }^{41}$ If the interaction between the GO membrane and the substrate is not strong enough, the GO membrane will be easily peeled off. Besides, the drying-related shrinkage of the GO membrane on rigid substrates such as a ceramic membrane will produce enormous tensile stress in the GO membrane and lead to defects. ${ }^{42}$

\section{Strategies for improving the stability of GO membranes in water}

The stability of GO membranes in water is a precondition for practical applications. So far, many efforts have been devoted to solving this problem, and some effective strategies have been developed. For example, the stability of GO membranes in water can be improved via covalent cross-linking, non-covalent crosslinking, and protective coating. ${ }^{43-47}$

\subsection{Improving the stability of the GO membrane itself}

3.1.1 Covalent cross-linking. One of the instability problems of the GO membrane is the disintegration or re-dispersion of GO nanosheets in water. Covalent cross-linking is an effective strategy to solve this problem. The functional groups such as carboxyl groups and hydroxyl groups on the GO nanosheets provide convenient sites for covalent cross-linking with different kinds of cross-linking agents. Mi et al. prepared a GO membrane crosslinked by 1,3,5-benzenetricarbonyl trichloride via a covalent reaction between carboxyl groups and acyl chloride, and they found that the cross-linking effectively provided the GO membrane with necessary stability to overcome its inherent dispensability in a water environment (Fig. 3A). ${ }^{48}$ Due to the covalent reaction between amino groups and carboxyl groups on the GO nanosheets, molecules or nanoparticles (NPs) with two or more amino groups have also been utilized as cross-linking agents to improve the stability of the GO membrane in water (Fig. 3B). ${ }^{49-66}$

Furthermore, glutaraldehyde $\mathrm{e}^{67}$ and 1-allyl-3-vinylimidazolium chloride $^{68}$ have also been utilized as cross-linking agents to improve the stability of the GO membrane in water. Although covalent cross-linking can endow the GO membranes with enough stability in water, the excessive cross-linking will disturb and block water transport within the GO nanochannels, leading to the decrease of the water flux of the membrane. So, how to improve the stability of the GO membrane in water, while maintaining or improving the water permeation flux is still a challenge. An effective strategy is to adjust the $d$-spacing via changing the chain length of the cross-linking agent, which can increase the water flux to some extent (Fig. 4A and B). ${ }^{49,58}$ Another method is to incorporate some NPs decorated with cross-linking groups. These NPs can not only act as crosslinking agents, but also adjust the interlayer spacing to increase the water flux (Fig. 4C). ${ }^{61,64}$ Besides organic molecules, metal ions $\left(\mathrm{Al}^{3+}, \mathrm{Fe}^{3+}, \mathrm{La}^{3+}, \mathrm{Ca}^{2+}, \mathrm{Mg}^{2+}, \mathrm{Ni}^{2+}\right.$, etc. $)$ can also act as crosslinking agents to improve the stability of GO membranes in water (Fig. 5A and B). ${ }^{37,69-73}$ This is because the GO nanosheets can be cross-linked by a multivalent cationic metal via formation

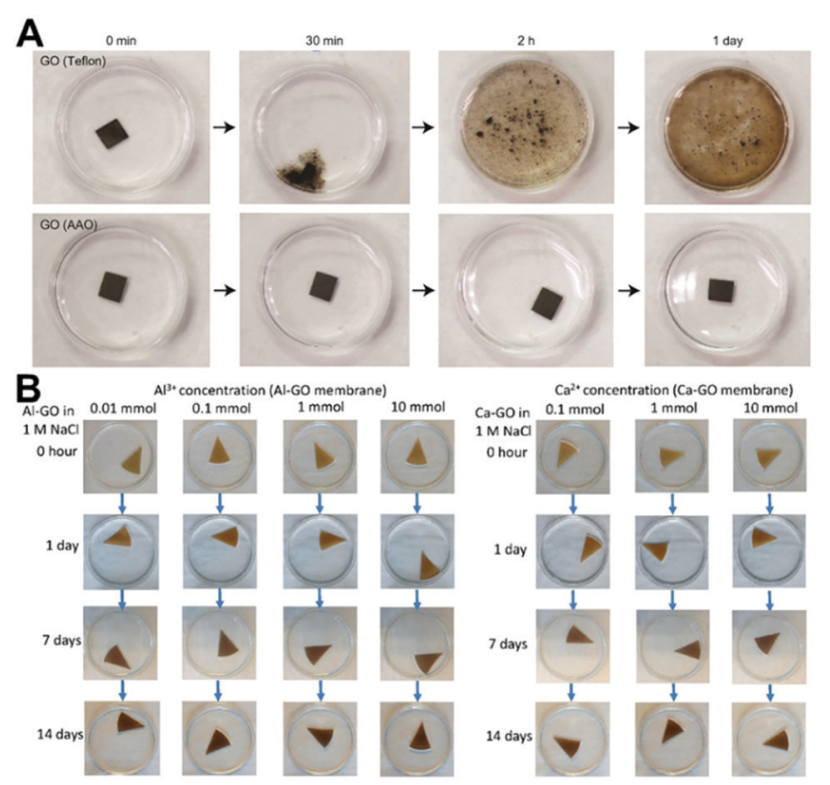

Fig. 5 (A) GO membranes obtained from Teflon and porous anodized aluminium oxide (AAO) filters, which have different stabilities in water. ${ }^{37}$ (B) Variation of $\mathrm{Al}-\mathrm{GO}$ and $\mathrm{Ca}-\mathrm{GO}$ membrane stability with cation quantity in a $1 \mathrm{M} \mathrm{NaCl}$ solution. ${ }^{69}(\mathrm{~A})$ and (B) were reprinted with permission from ref. 37 and 69 , respectively.

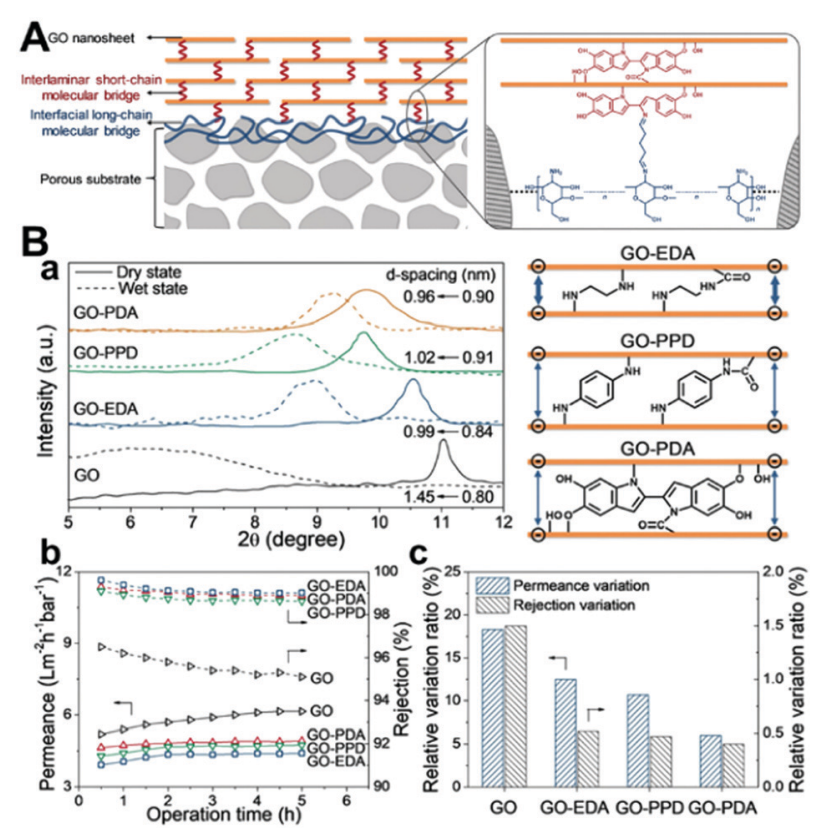

Fig. 6 (A) Schematic illustration for stabilizing a GO membrane through hierarchical interlaminar short-chain and interfacial long-chain molecular bridges. (B) Anti-swelling capabilities of interlaminar short-chain molecularbridged GO membranes; (a) XRD patterns (left) of pristine GO and EDA-, PPD-, and PDA bridged GO membranes (color coded). (b) Operation time dependence of water permeance and rejection of pristine GO and EDA-, PPD-, and PDA-bridged GO membranes. (c) Relative variation ratios of water permeance and rejection of pristine GO and EDA-, PPD-, and PDA-bridged $\mathrm{GO}$ membranes. $(\mathrm{A})$ and $(\mathrm{B})$ were reprinted with permission from ref. 63. 
of a coordination bond. These above-mentioned strategies can effectively improve the water permeation flux, but the swelling is still obvious, which may result in a decrease in the rejection rate.

In fact, the instability of GO membranes in water refers to not only the disintegration, but also the swelling that is often ignored. Swelling (without disintegration) can lead to an unstable separation performance (rejection rate). Therefore, restraining swelling is also important to solve the instability of GO membranes in water. Most recently, Jin et al. reported a molecular bridge strategy, in which an interlaminar short-chain molecular bridge generates a robust GO laminate that resists the tendency to swell, while an interfacial long-chain molecular bridge adheres the GO laminate onto a porous substrate to increase the mechanical strength of the membrane (Fig. 6). ${ }^{63}$ By rationally creating and tuning the molecular bridges, the stabilized GO membranes exhibit outstanding durability under harsh operating conditions, such as cross-flow, high-pressure, and long-term filtration. ${ }^{63}$ Besides, this strategy is universal for various porous substrates such as ceramics, nylon and mixedcellulose acetate. Moreover, this strategy is also scalable. This versatile approach will open up new opportunities for GO membranes used in aqueous environments. ${ }^{63}$

In brief, amine-based molecules can give a stable membrane structure because the GO nanosheets can be effectively crosslinked via a covalent reaction. However, excessive cross-linking will disturb and block water transport within the GO nanochannels, leading to a decrease in the water flux of the membrane. Therefore, endowing the GO NF membrane with excellent stability while maintaining the high permeation flux and precise separation performance of the membrane are very important.

3.1.2 Non-covalent cross-linking. Besides covalent crosslinking, non-covalent cross-linking via van der Waals forces, hydrophobic interactions, $\pi-\pi$ interactions, electrostatic and hydrogen bonding interactions has also been utilized to improve the stability of the GO NF membranes in water.

Incorporation of reduced graphene oxide (rGO) or partial reduction of GO membranes can effectively alleviate the swelling of GO membranes, making the GO membranes stable in water. This is because the partially reduced GO nanosheets can provide enough van der Waals forces ( $\pi-\pi$ stacking) and hydrophobic interactions to overcome the repulsive hydration and electrostatic repulsion between adjacent negatively charged GO layers. It has been reported that rGO NF membranes exhibit excellent stability in water. ${ }^{31,75,76}$ However, a narrowed interlayer space between the rGO layer caused by the reduction, as well as the hydrophobic nature of the rGO, significantly decrease the water permeation flux of the resultant membranes. Utilization of partially reduced GO to fabricate GO/rGO composite NF membranes is an effective strategy to diminish the decrease in water flux (Fig. 7). ${ }^{38,74,77-81}$ The partially reduced GO can lead to weakened repulsive hydration
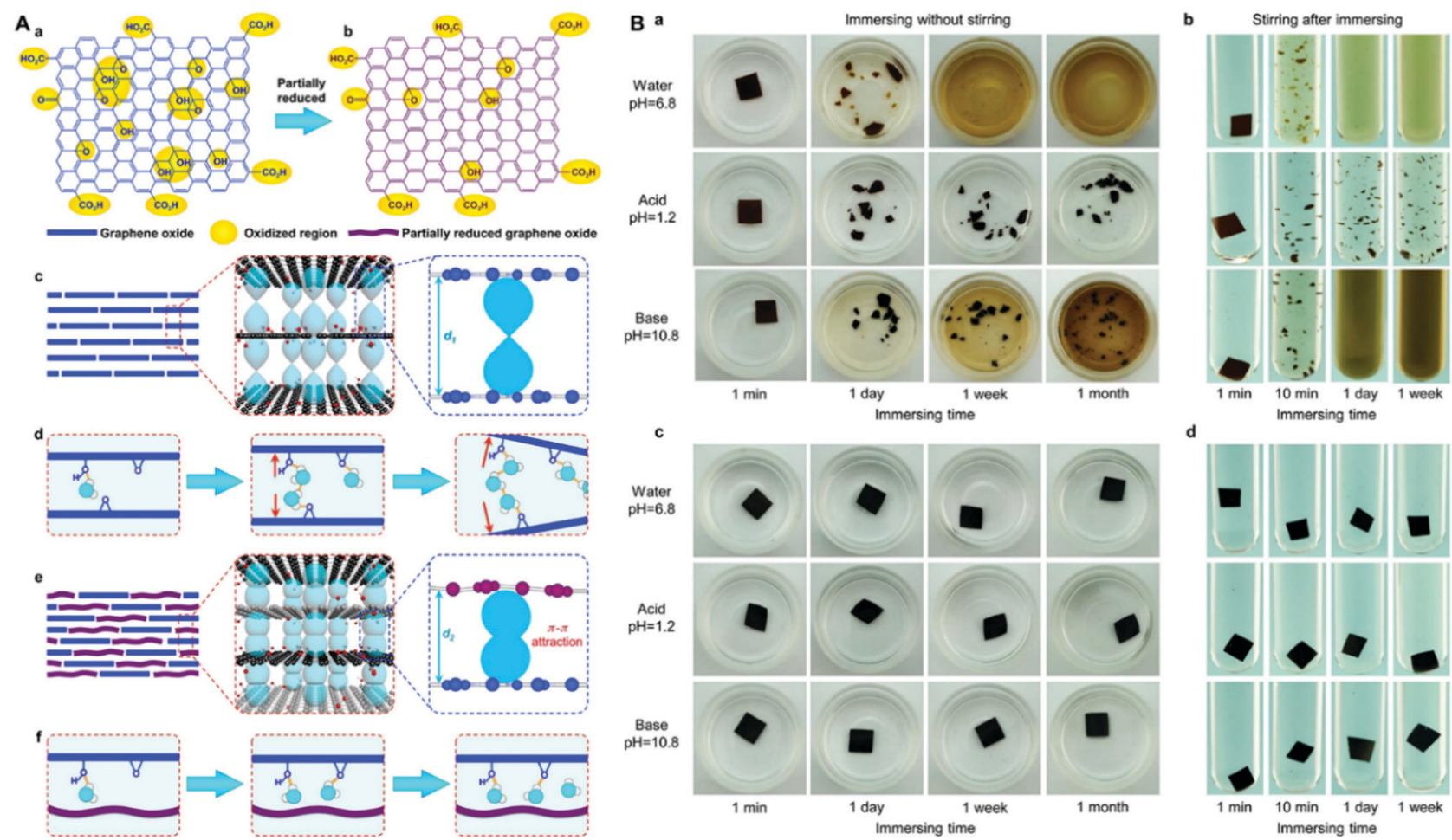

Fig. 7 (A) Schematic illustration of the fabrication strategy and mechanism of the partially reduced graphene oxide (pfGO)-doped GO membranes with high stability in aqueous solutions and controllable lamellar spacing. ${ }^{74}$ The GO sheets with plentiful oxidation regions (a) are partially reduced to prGO sheets (b). The pure GO membranes have a large inter layer spacing $d_{1}(\mathrm{c})$ and more oxidation groups on lamellar sheets, leading to a stronger repulsive hydration force making the GO membranes disintegrate in aqueous solutions (d). The prGO-doped membranes have a closer interlayer spacing $d_{2}$ that creates stronger $\pi-\pi$ attractions between GO sheets (e) and a weak repulsive hydration force to keep GO membranes stable in aqueous solutions ( $f$ ). (B) Stability of GO@Teflon membranes in water, acid, and base solutions. ${ }^{74}$ (a and b) GO@Teflon membranes prepared with 0 wt\% prGO. (c and d) GOaTeflon membranes doped with $50 \mathrm{wt} \% \mathrm{prGO}$. (A) and (B) were reprinted with permission from ref. 74. 
and enhanced $\pi-\pi$ attraction in GO NF membranes, while the hydrophilic GO can provide water permeation channels with enough interlayer space. Based on GO and rGO, Morelos-Gomez et al. proposed an easy, scalable, low-energy and environmentally friendly spray-coating deposition method to fabricate a GO/rGO NF membrane. ${ }^{77}$ Due to the synergistic effect of GO and rGO, as well as the distinct method, the resultant GO/rGO membrane possesses enhanced shear resistance, good filtration and chlorine resistance, making this kind of membrane attractive for prolonged use with chemical endurance. ${ }^{77}$
Since the rGO plays very important roles, the detailed influence of the reduction degree of GO or the additive amount of rGO on the performance of the resultant membrane should be investigated. By controlling the content of oxidized groups via changing the reducing conditions, Chu et al. prepared GO/rGO membranes with different lamellar distances and studied the influence of lamellar distance on the stability of the obtained GO/rGO membranes (Fig. 8). The authors provided a critical lamellar distance that varies in aqueous solutions depending on $\mathrm{pH}$ values and found that if the lamellar distance is less than the critical value, the membrane could be
A a
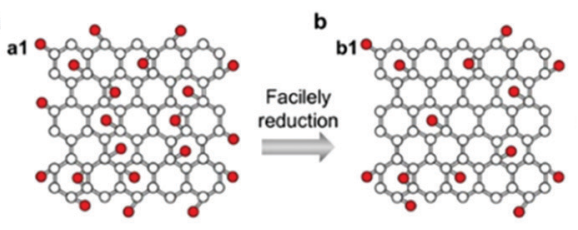

a2

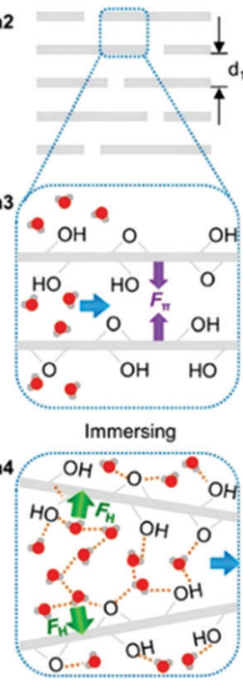

b2
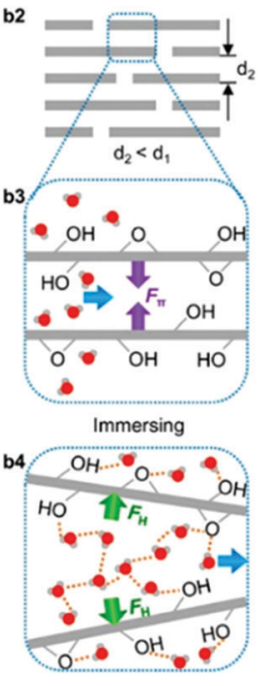

Unstable $\left(F_{\mathrm{H}}>F_{\mathrm{H}}\right)$

Unstable $\left(F_{H}>F_{H}\right)$

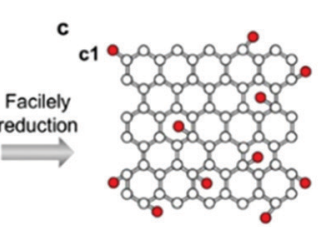

c2

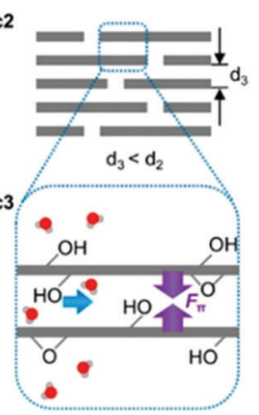

Immersing

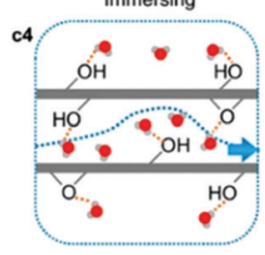

Stable $\left(F_{\mathrm{H}}<F_{\mathrm{H}}\right)$

B a

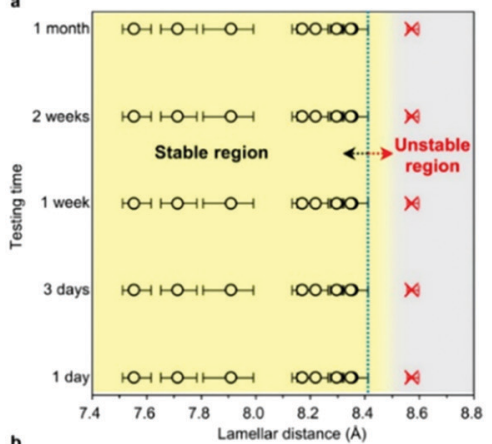

b

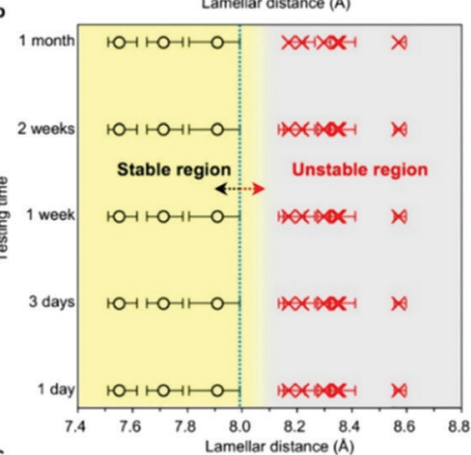

d

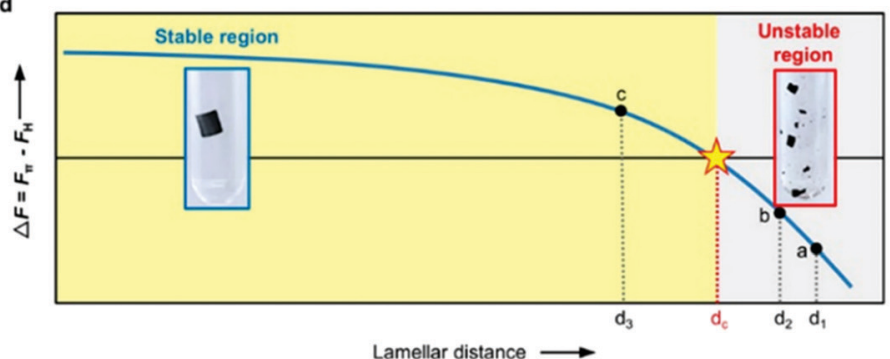

Fig. 8 (A) Schematic illustration of the effect of lamellar distances on the stability of graphene-based membranes. ${ }^{38}$ (a) A GO membrane that was stacked by pristine GO nanosheets with plenty of oxidized groups is unstable in aqueous solution due to the weak $\pi-\pi$ attraction force $\left(F_{\pi}\right)$ and the strong hydration repulsive force $\left(F_{H}\right)$. (b) A facilely reduced graphene oxide (FRGO) membrane that was stacked by the FRGO nanosheets with mild reduction is still unstable in aqueous solution although the $F_{\pi}$ increases to some extent. (c) An FRGO membrane that was stacked by the FRGO nanosheets with a large reduction degree is stable in aqueous solution due to the increased $F_{\pi}$ and decreased $F_{H}$. (d) Schematic relationship between the lamellar distance and the $\Delta F\left(\Delta F=F_{\pi}-F_{H}\right)$ inside the graphene-based membranes. The gray region represents the unstable membranes, while the yellow region represents the stable membranes. The red dashed line represents the critical lamellar distance $\left(d_{\mathrm{c}}\right)$. (B) Systematic results on the stability of graphenebased membranes with diverse oxidized-group-supported lamellar distances in acidic solutions ( $\mathrm{pH} 1.0)(\mathrm{a})$, water $(\mathrm{pH} 6.6)(\mathrm{b})$, and basic solutions (pH 11.2) (c) using a stirring test during different time periods. ${ }^{38}$ The black circles mean that the membranes are intact, and the red crosses mean that the membranes are broken at the observation moment. The blue dotted lines mark the estimated critical lamellar distance of graphene-based membranes for different situations. The yellow regions represent the range of lamellar distances of stable graphene-based membranes in aqueous solutions, while the gray regions represent the unstable membranes. (A) and (B) were reprinted with permission from ref. 38. 
physically stable and exhibit good water permeation performance in water for a long time. ${ }^{38}$ Ren et al. found that weak reduction increased the number of pristine graphitic $\mathrm{sp}^{2}$ domains in rGO nanosheets while keeping the large interlayer spacing of the GO membranes in most regions at the same time, endowing the resultant membrane with better structural stability and
A a

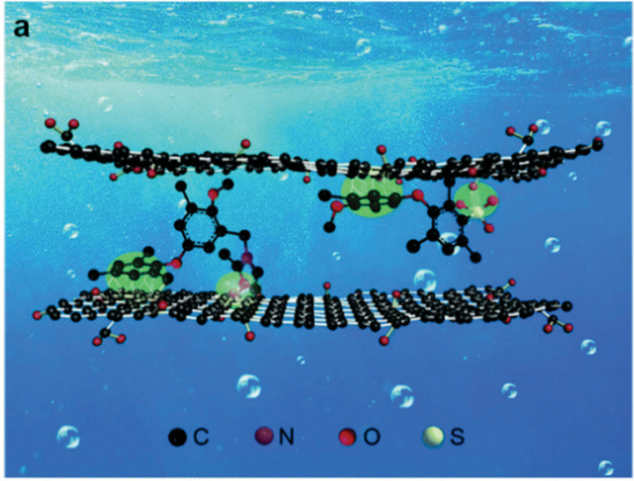

b

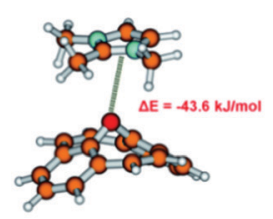

B

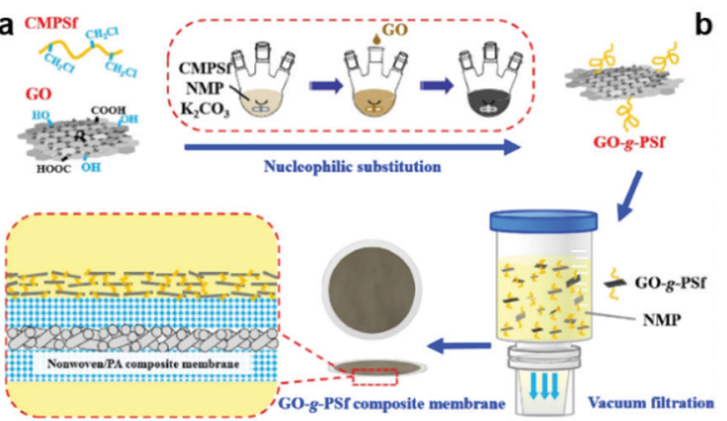

c

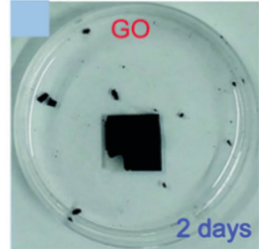

Solvated

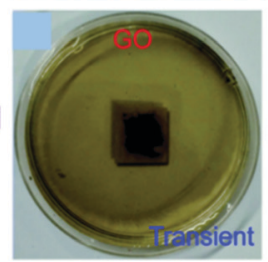

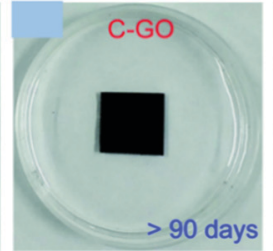
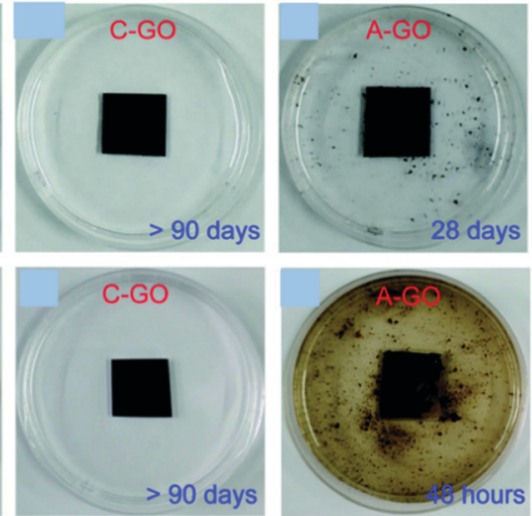

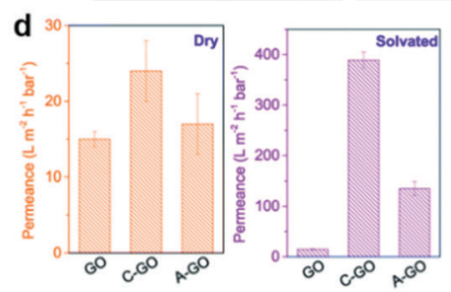

b

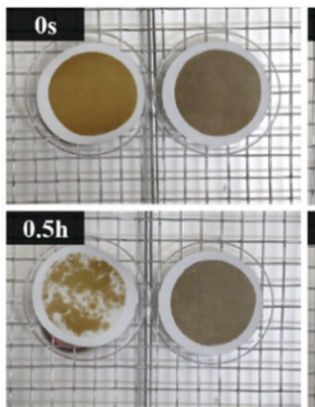

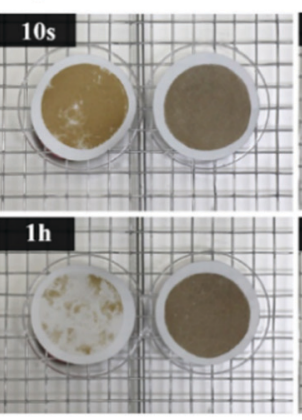

20s

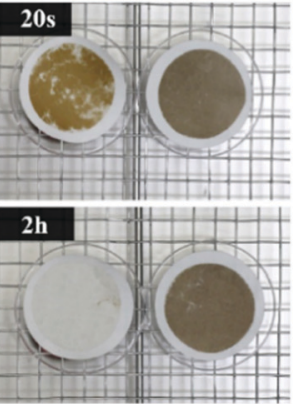

C a

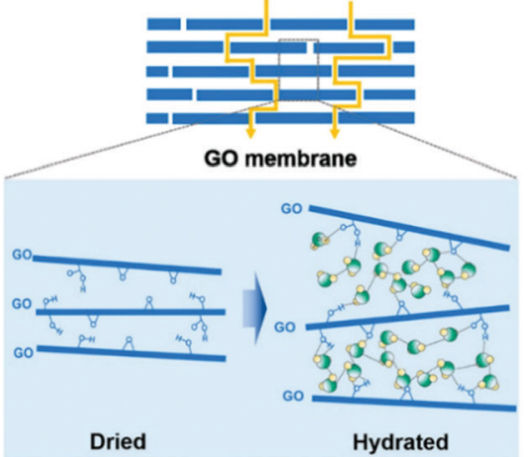

$\times \times x \times 3 \times x$

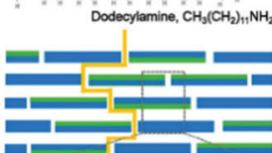

GO/JGO composite membrane

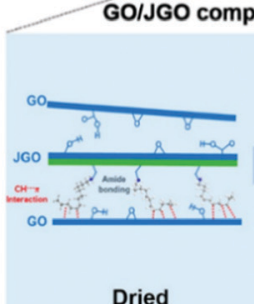

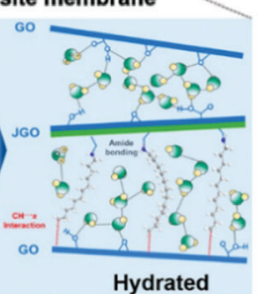

b

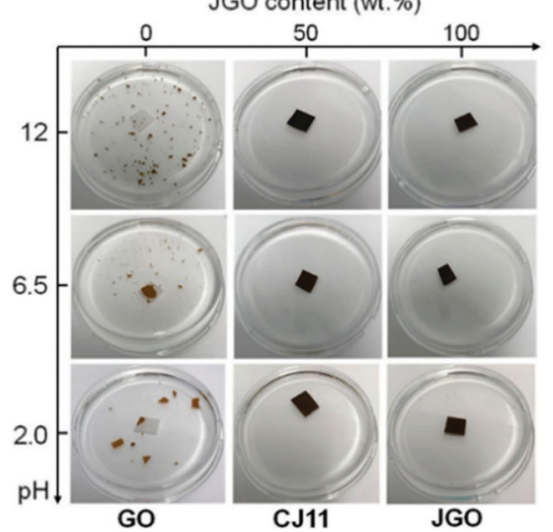

Fig. 9 (A) Non-covalent cross-linking to boost the stability of GO membranes. ${ }^{82}$ (a) Illustration of non-crosslinking GO membranes via $\pi-\pi$, electrostatic and hydrogen bonding interactions. (b) The models used for calculating the binding energies between Im cations on Im-PPO and epoxy on the GO as well as between sulfonic acid on the S-PPO and GO. (c) Stability of dry and solvated GO, C-GO and A-GO membranes in water. (d) Permeance and rejection of EB dye solutions of dry and solvated GO, C-GO and A-GO membranes. (B) A polysulfone-grafted GO membrane. ${ }^{92}$ (a) Schematic diagram of the GO-g-PSf composite membrane fabrication. (b) Photographs of a GO composite membrane (M-GO-0.4, left) and GO-g-PSf composite membrane (M-GP-0.4, right) at different times during the ultrasonic irradiation experiment. CMPSF: chloromethylated polysulfone. (C) Janus GO (JGO)-doped composite membranes. ${ }^{94}$ (a) Illustration of molecular transport through the nanochannel constructed in (a) GO lamellar membranes and (b) JGO-doped composite membranes. (b) Membranes with different $\mathrm{JGO}$ contents at $\mathrm{pH}=2, \mathrm{pH}=6.5$, and $\mathrm{pH}=12$ after being soaked in water for $2 \mathrm{~h}$ with mechanical agitation. (A-C) were reprinted with permission from ref. 82, 92 and 94, respectively. 
A $\mathrm{a}_{\text {Feed: }} \leq 10 \%$ water

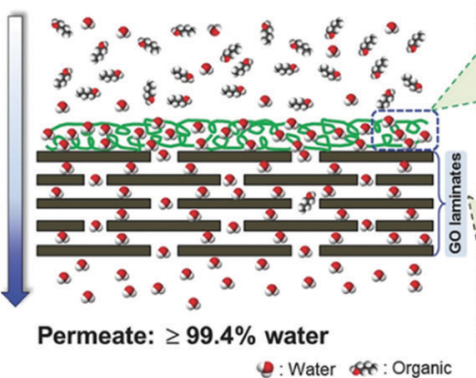

Functions of a CNT protective layer:

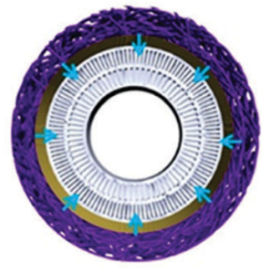

Mechanical confinement

High stability

C a
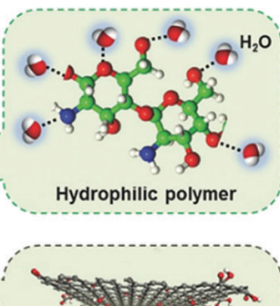
-ciscouritio

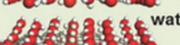

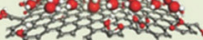

Go laminar channels
Hydrophilic polymer

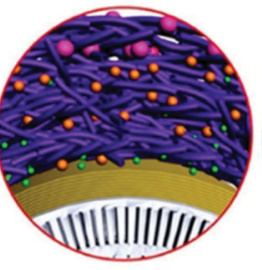

Pre-filtration Increasing electroconductivity $\downarrow$ High antifouling ability

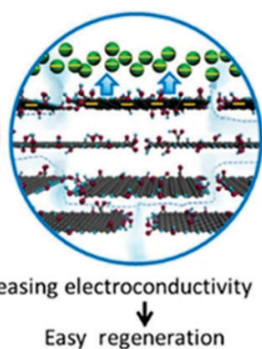

b $\operatorname{Tr}_{\text {stage }}$

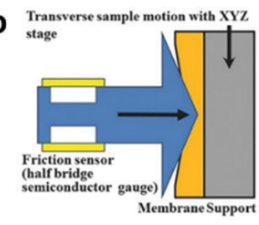

d

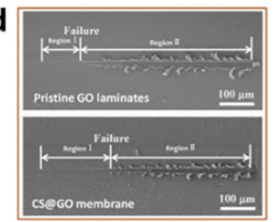

b

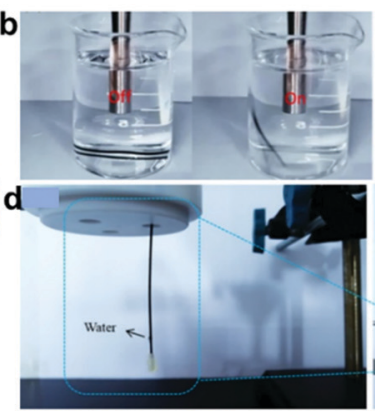

b

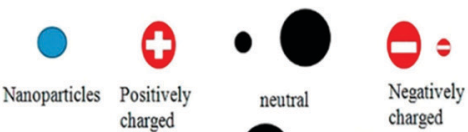

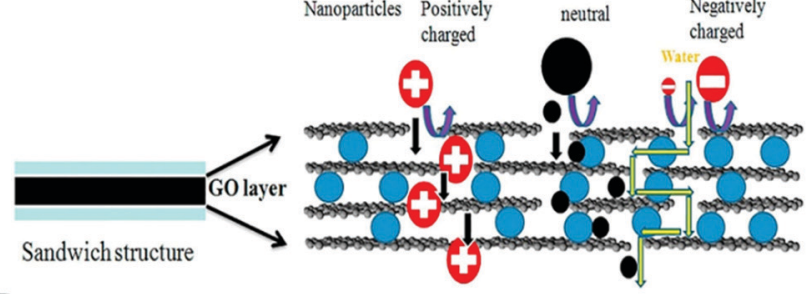

D

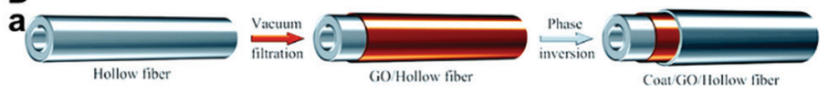

b

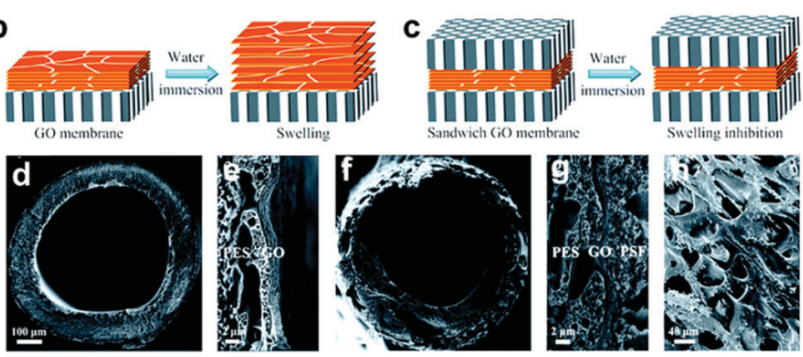

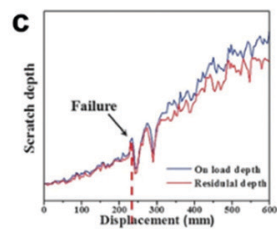

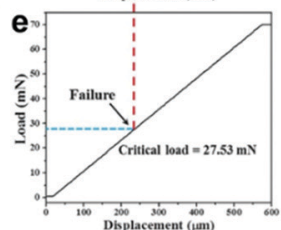

C
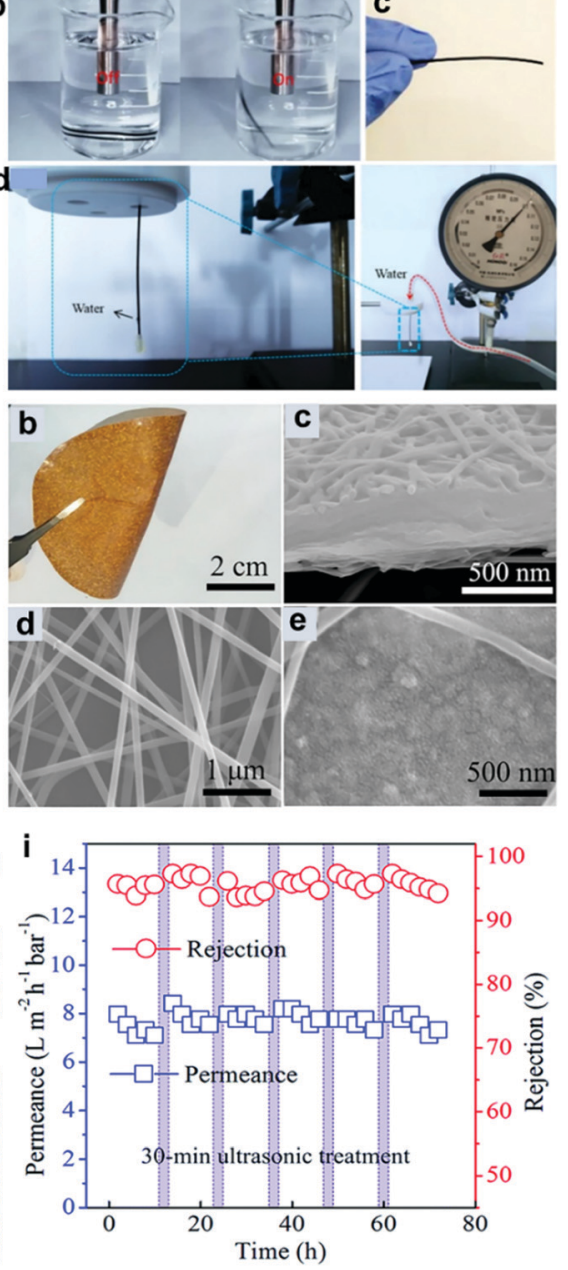

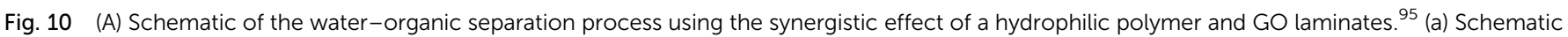

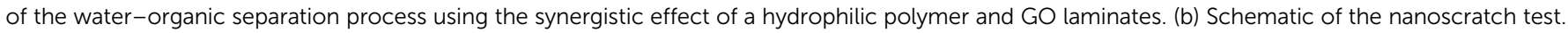

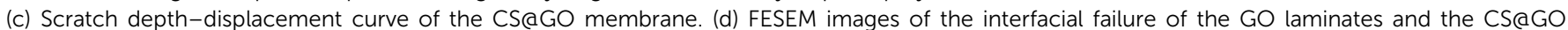

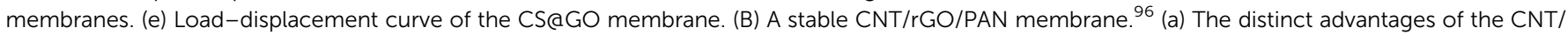

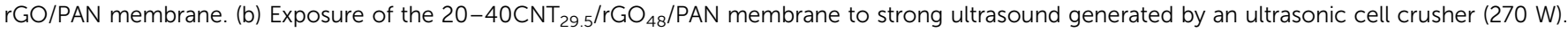

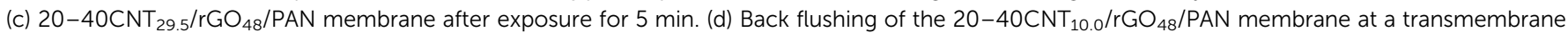

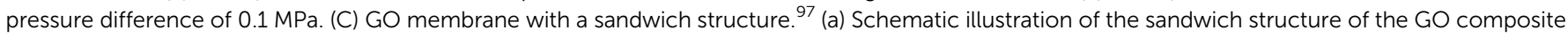

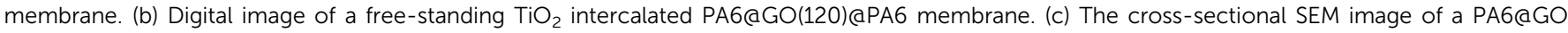

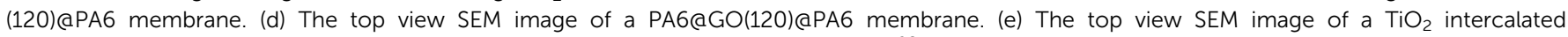

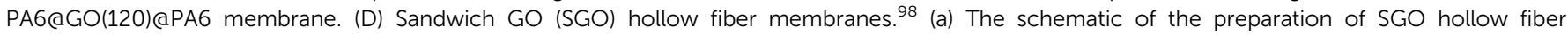

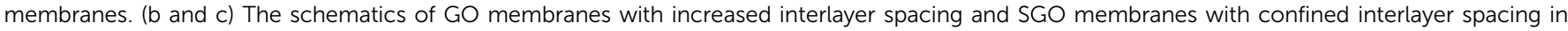

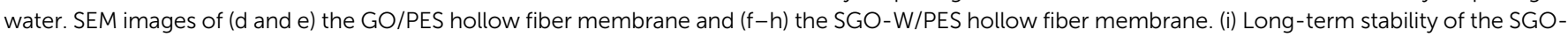

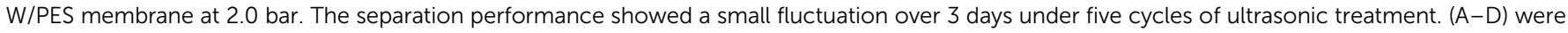
reprinted with permission from ref. 95-98, respectively. 
separation performance than GO membranes in acid and alkali environments. $^{78}$

Although incorporation of rGO can improve the stability of GO membranes in water, the rGO incorporated in GO membranes will decrease channel sizes and solvation levels due to the loss of oxygen sites, which may cause barriers for water entry and subsequent transport. ${ }^{82}$ Incorporation of other nanomaterials can increase the $d$-spacing, thus improving the water flux while maintaining enough stability in water. So far, many kinds of nanomaterials such as CNTs, ${ }^{83-85} \mathrm{Fe}_{3} \mathrm{O}_{4},{ }^{86} \mathrm{TiO}_{2},{ }^{86} \mathrm{UiO}-66,{ }^{86}$ attapulgite, ${ }^{87}$ niobate nanosheets, ${ }^{88} \mathrm{MoS}_{2},{ }^{89}$ boron nitride nanosheets, ${ }^{90}$ and MXenes ${ }^{91}$ have been utilized to improve the stability and permeation of GO membranes.

However, the rejection property of the GO membranes incorporated with nanomaterials was reduced significantly due to the fact that it was difficult to regulate the intercalating materials and achieve evenly-distributed deposition between interlayers. ${ }^{86,92}$ Compared with incorporated nanomaterials, polymers can be better distributed on GO nanosheets, thus they can significantly decrease the disarranged laminar structure and larger interlayer spacing, achieving improved water flux and dye rejection. ${ }^{92,93}$ Most importantly, the entanglement of polymer chains grafted on GO nanosheets can provide enough interaction to maintain the structural stability of the GO membrane in water. $\mathrm{Xu}$ et al. reported an effective strategy to prepare highly stable GO NF membranes by intercalating ionic polymers rich in benzene and cationic imidazolium (or anionic sulfonic acid) moieties (Fig. 9A). ${ }^{82}$ The incorporated ionic polymers can non-covalently cross-link neighbouring GO nanosheets via $\pi-\pi$, electrostatic and hydrogen bonding interactions. Li et al. reported a strategy to improve the structural stability and water permeance of GO membranes by grafting polysulfone onto GO nanosheets (Fig. 9B). ${ }^{92}$ Wang et al. prepared amphiphilic Janus GO nanosheets by modification of one side of the GO nanosheets with dodecylamine and found that the Janus GO nanosheets can strengthen interactions among neighbouring GO nanosheets and thus prevent structural disintegration in water (Fig. 9C). ${ }^{94}$

3.1.3 Protective coating. As has been mentioned, crosslinking agents in the GO membrane will disturb and block water transport, resulting in the decrease in water flux. An alternative is to utilize a protective coating. Unlike the crosslinking agents in the channels of a GO NF membrane, the protective layer is on the outer surface of the GO membrane. Thus, the transport channels of GO NF membranes can be fully utilized to obtain fast water transport. Moreover, the whole layer on the surface of the GO NF membrane can act as a protective coating to increase the stability in water.

Jin et al. prepared a hydrophilic polymer layer on a GO membrane, and found that the polymer layer can efficiently improve the mechanical stability of the GO membrane (Fig. 10A). ${ }^{95}$ Zhao et al. reported a structurally durable rGO NF membrane coated with a carbon nanotube (CNT). The CNT protective layer cross-linked by polyvinyl alcohol and succinic acid can endow the GO membrane with high-pressure (at least 1 bar) back-flushing (Fig. 10B). ${ }^{96}$ In fact, besides stability, the protective coating can also provide other benefits such as anti-fouling and easy regeneration, ${ }^{96}$ making it a potential way to fabricate high-performance GO NF membranes. Lou et al. prepared a sandwich-structured GO NF

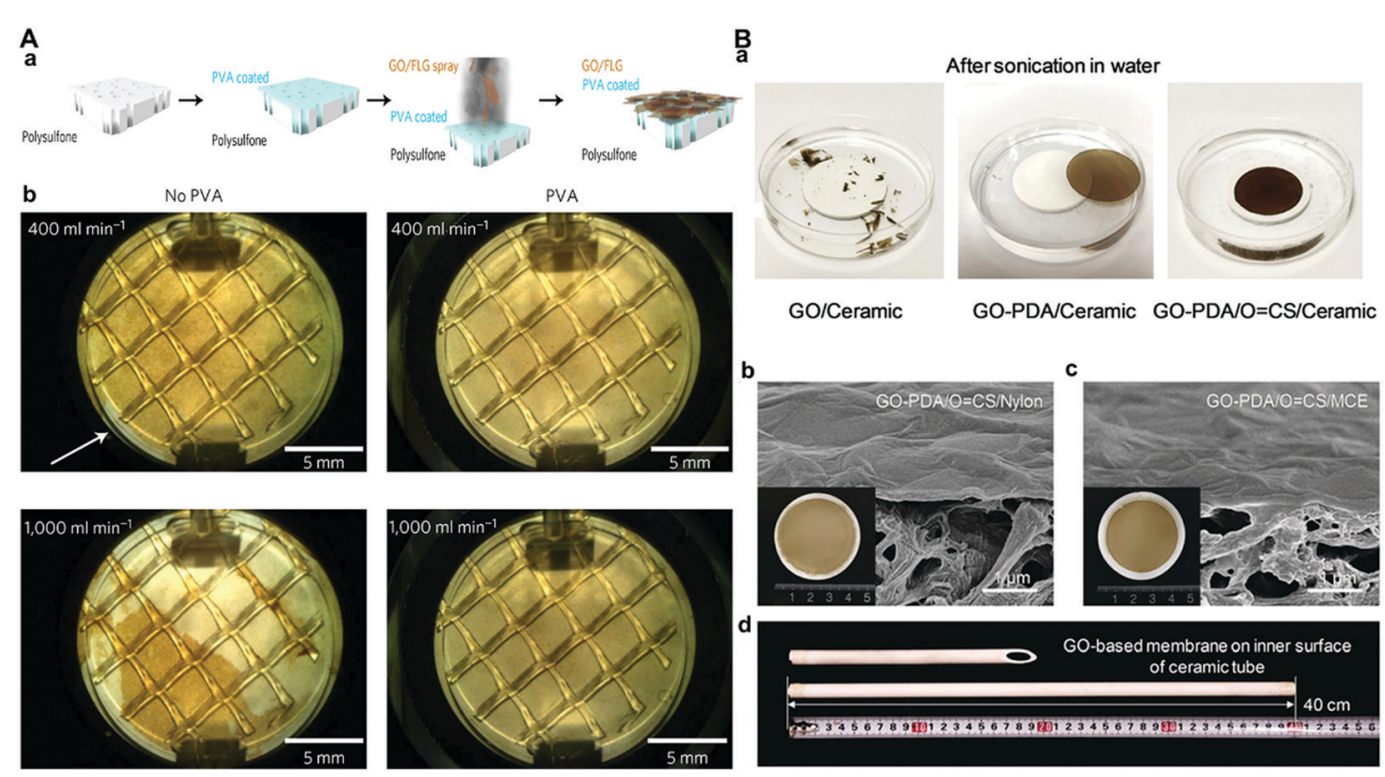

Fig. 11 (A) GO/FLG membrane preparation. ${ }^{77}$ (a) Porous polysulfone substrate, PVA coating on the substrate (blue); the GO/FLG solution is deposited by spray-coating the composite membrane with the GO and FLG sheets oriented parallel to the surface. (b) Photographs of GO/FLG membranes without and with PVA as the intermediate layer after 60 min under cross flows of 400 and $1000 \mathrm{~mL} \mathrm{~min}{ }^{-1}$ at $1 \mathrm{MPa}$ for $1 \mathrm{~h}$. PVA considerably improves membrane adhesion, as seen on the images under a cross-flow of $1000 \mathrm{~mL} \mathrm{~min}{ }^{-1}$. The white arrow indicates the area where peel-off begins. (B) Nanofiltration performance of a GO-PDA/O $=\mathrm{CS} /$ ceramic membrane. ${ }^{63}$ (a) Photographs of GO/ceramic, GO-PDA/ceramic, and GO-PDA/O $=\mathrm{CS} / \mathrm{ceramic}$ membranes after high-power sonication for $30 \mathrm{~min}$ in water. Cross-sectional SEM images of (b) GO-PDA/O $=\mathrm{CS} /$ nylon and (c) GO-PDA/O $=\mathrm{CS} / \mathrm{MCE}$ membranes. MCE: mixed-cellulose acetate. Insets are photographs of each membrane. (d) Photograph of the scaled inner surface of the GO-PDA/O=CS/ceramic membrane with $40 \mathrm{~cm}$ length. (A) and (B) were reprinted with permission from ref. 77 and 63, respectively. 
membrane via an electrospraying/electrospinning method, and found that the GO NF membrane coated with polyamide nanofiber networks can remain stable even under ultrasonication (Fig. 10C). ${ }^{97}$ Most recently, Li et al. reported that the out-of-plane swelling and interlayer-spacing expansion of GO membranes in water can be suppressed bilaterally using porous coats and hollow fiber substrates (Fig. 10D). ${ }^{98}$

\subsection{Improving the interfacial stability between the GO layer and substrates}

Another instability problem is that GO membranes easily peel off the underlying substrate due to the insufficient interfacial adhesion between the GO layer and substrate, ${ }^{63}$ which severely limits its practical application. Surface modification of the substrates is an effective way to improve the interfacial interaction between substrates and GO nanosheets. For example, the modification of a ceramic support by saline can improve interfacial adhesion with the GO layer. ${ }^{99}$ Morelos-Gomez et al. used a polysulfone membrane coated with polyvinyl alcohol (PVA) as the substrate to improve the interfacial interaction and found that the obtained GO membrane achieved a steady
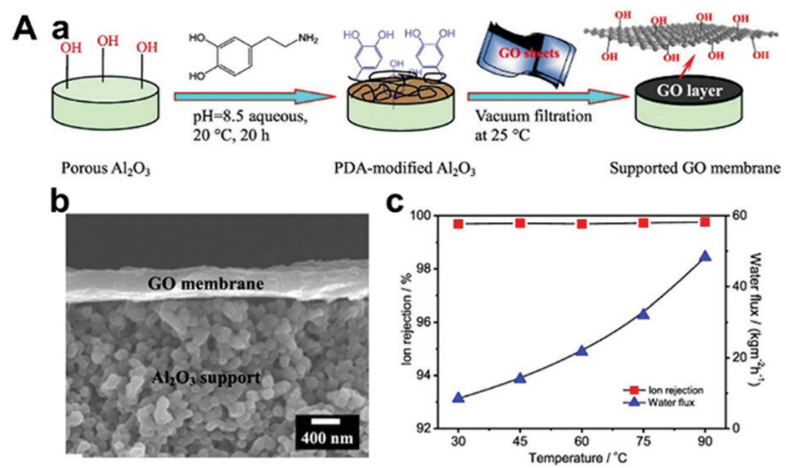
PDA-modified $\mathrm{Al}_{2} \mathrm{O}$

Supported GO membrane

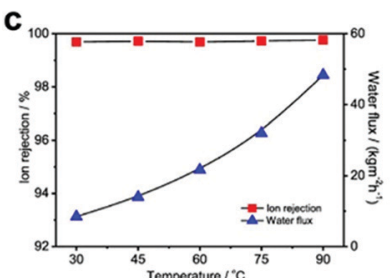

B a

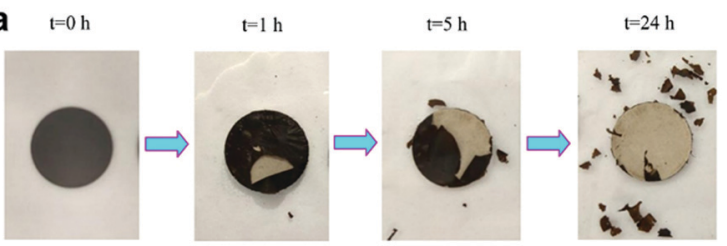

b $\quad \mathrm{t}=0 \mathrm{~h}$

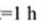

$\mathrm{t}=5 \mathrm{~h}$

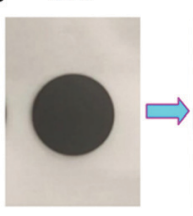

$\mathrm{t}=1 \mathrm{~h}$
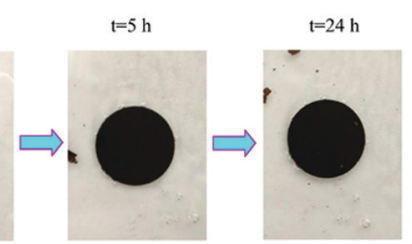

Fig. 12 (A) Highly stable GO membrane based on PDA functionalized supports. $^{113}$ (a) Schematic diagram of the synthesis of GO membranes on the PDA-modified $\alpha-\mathrm{Al}_{2} \mathrm{O}_{3}$ supports through a vacuum filtration method. (b) FESEM images of the GO membrane prepared on a PDA-modified $\mathrm{Al}_{2} \mathrm{O}_{3}$ disk. (c) Ion rejection and water flux of the $\mathrm{GO}$ membrane prepared on a PDA-modified $\mathrm{Al}_{2} \mathrm{O}_{3}$ disk as a function of the operating temperature for desalination of $3.5 \mathrm{wt} \%$ seawater by pervaporation. (B) Photographs of the GO membrane prepared on (a) the non-modified and (b) the PDAmodified $\alpha-\mathrm{Al}_{2} \mathrm{O}_{3}$ disks as a function of placing time in air at $25^{\circ} \mathrm{C} .{ }^{113}$ (A) and (B) were reprinted with permission from ref. 113 performance for up to $120 \mathrm{~h}$ under intense cross-flow with the help of the PVA intermediate layer (Fig. 11A). ${ }^{77}$ Jin et al. designed aldehyde (glutaraldehyde or maleic anhydride)modified chitosan $(\mathrm{O}=\mathrm{CS})$, with a moderate molecular weight and abundant functional groups, as the interfacial longchain molecular bridge, ${ }^{63}$ and found that the $\mathrm{O}=\mathrm{CS}$ can offer sufficient physical and chemical interactions between the substrate and the GO layer, avoiding the peeling off of the GO layer from the substrate even under a harsh water separation process (Fig. 11B). ${ }^{63}$
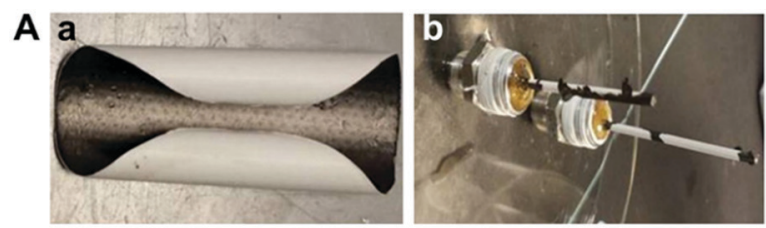

B
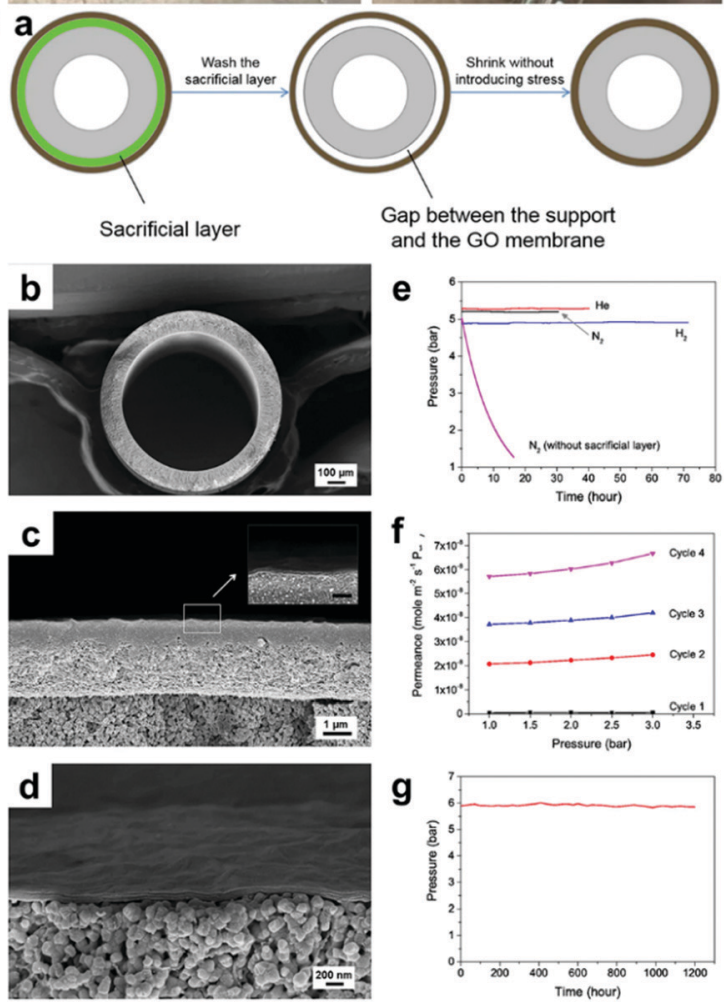

Fig. 13 (A) Drying-related shrinkage of GO membranes on supports. ${ }^{42}$ Photographs of (a) a GO membrane supported by a PES polymeric filter, and (b) a GO membrane supported by an alumina hollow fiber. (B) Sacrificial layer stabilised GO membranes. ${ }^{116}$ (a) A scheme of the working principle of the use of sacrificial layer to stabilise the GO membrane on a hollow fibre substrate. (b) The whole view of the cross section of an yttrium stabilised zirconia (YSZ) hollow fibre. (c) A SEM image showing the GO/PMMA/YSZ tri-layer structure, where the sacrificial PMMA layer is sandwiched in the middle by the top GO layer and the bottom YSZ substrate (Scale bar $=200 \mathrm{~nm}$ in the smaller image). (d) A SEM image showing the GO/YSZ structure after the PMMA layer was washed with acetone. (e) The results of gas tightness tests of the GO/YSZ hollow fibre membrane prepared using a sacrificial layer. (f) The result of repeated $\mathrm{N}_{2}$ gas permeation tests of a dry GO/YSZ hollow fibre membrane without using a sacrificial layer. (g) The result of a long-term stability test with $\mathrm{O}_{2}$ on a $150 \mathrm{~nm}$-thick sacrificial layer stabilised GO/YSZ hollow fibre. (A) and (B) were reprinted with permission from ref. 42 and 116, respectively. 
Considering the diversity of substrates available for supporting GO membranes, it is necessary to develop a universal method to realize the surface modification of various substrates. Musselinspired adhesive materials such as polydopamine (PDA), tannic acid, and other polyphenols can form coatings with active groups on almost any substrate surface, making these coatings a powerful tool for surface modification.,100-112 Thanks to the high adhesive ability of PDA, GO nanosheets can be attracted and firmly bound to the surface of substrates, remarkably enhancing the stability of the GO membrane (Fig. 12). ${ }^{113-115}$

It should be noted that GO membranes on ceramic hollow fiber substrates are unstable in the dry state, mainly due to the drying-related shrinkage (Fig. 13A).$^{42}$ Li et al. demonstrated that a GO hollow fiber membrane can be stabilised using a porous poly(methyl methacrylate) sacrificial layer, which creates a space between the GO membrane and substrate thus allowing stressfree shrinkage (Fig. 13B). ${ }^{116}$

Most recently, B. Kaner et al. developed a novel thin-film liftoff (T-FLO) technique that enables the fabrication of robust
GO membranes (Fig. 14A). ${ }^{117}$ In detail, the active layer GO is cast onto a glass pane, and the thickness and chemistry of the GO selective layer can be facilely tuned during this casting process. Then, a fiber-reinforced, epoxy-based resin is cured on top of the GO layer to form a covalently bound support layer. After submersion in water, the cured membrane lifts off from the substrates, providing a robust, freestanding, asymmetric GO composite membrane. ${ }^{117}$ Compared with a common scenario such as the deposition of a GO film by filtering a GO suspension on substrates, the T-FLO method results in much stronger adhesion between the GO membrane and substrates. ${ }^{118}$ As a result, the obtained T-FLO-GO membrane can remain stable in water for at least 30 days (Fig. 14B), and it exhibits stable separation performance under different pressures and long-time operation. ${ }^{118}$

\section{Challenges and perspective}

Although significant progress has been made in improving the stability of GO NF membranes in an aqueous environment,

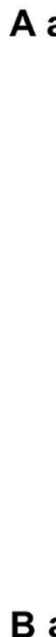

B a

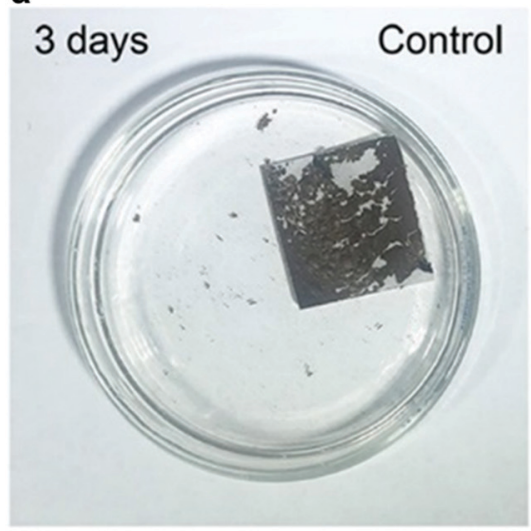

b

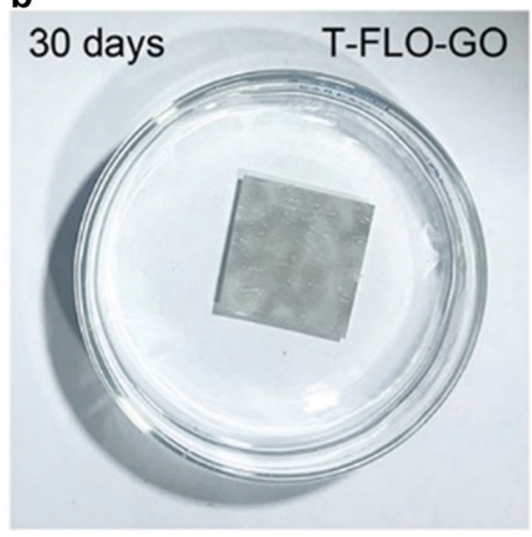

\section{b Common scenario}
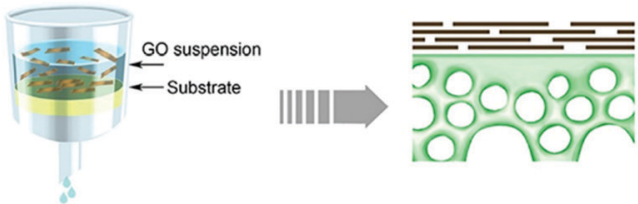

Minimal

adhesion
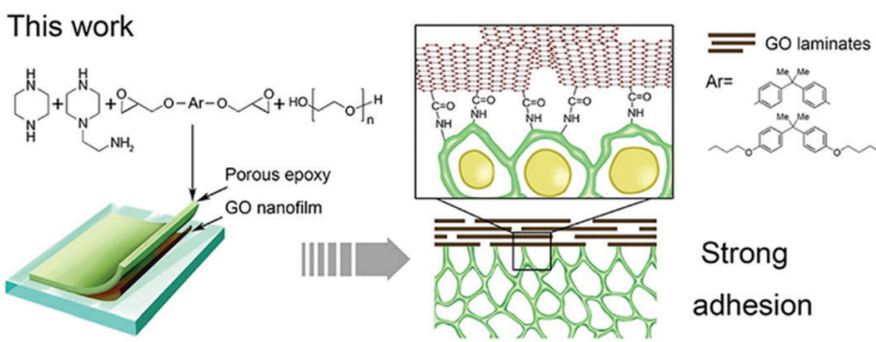

Strong

adhesion
C

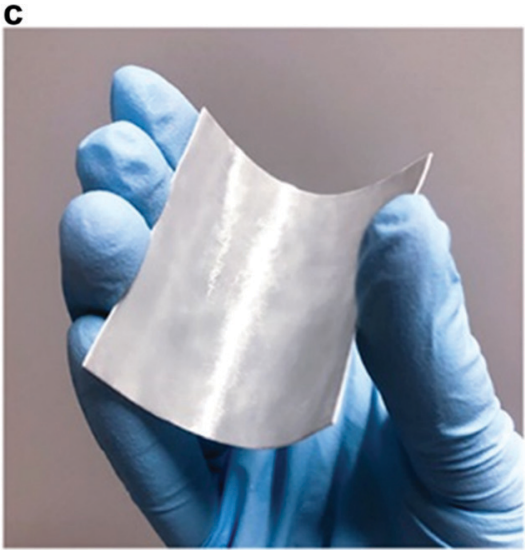

Fig. 14 (A) GO NF membranes based on thin-film liftoff (T-FLO). ${ }^{117}$ (a) Fabrication of thin-film lift off (T-FLO) membranes. The thin-film interference pattern created by a several-hundred-nanometers-thick active layer can be seen in the top right photograph. (b) Schematic of a nanostructured graphene oxide ( $T$-FLOGO) composite membrane. ${ }^{118}$ Common scenario: the deposition of a GO film by filtering a GO suspension onto a substrate (minimum adhesion in the composite structure). This work: post-polymerizing an epoxy layer with a percolating porous structure onto a GO nanofilm results in strong adhesion within the composite structure. (B) Mechanically robust T-FLO-GO membranes. ${ }^{118}$ (a) Photograph of a control in water for 3 days. The control was air-dried before being placed in water. (b) Photograph of a T-FLO-GO membrane immersed in water for 30 days. (c) Photograph of a bent T-FLO-GO membrane with a 32 nm-thick GO layer and a 9:1 diamine ratio epoxy. (A) and (B) were reprinted with permission from ref. 117 and 118, respectively. 
there are still some challenges for the commercial application of GO NF membranes.

Firstly, the long-term stability of the GO NF membrane is still a major concern. The testing time for the stability of GO membranes is only from several hours to a few months, which is far below the duration for practical applications. Therefore, the long-term stability of the GO NF membranes should be further investigated.

Secondly, the GO NF membranes should be resistant to back washing and chemical cleaning, as these operations are usually applied to resolve membrane fouling. However, GO membranes that can withstand back washing and chemical cleaning are still scarce.

Thirdly, the stable precise separation of GO NF membranes in water is still a challenge. It has been reported that a GO membrane can be reduced to rGO using certain operation conditions. ${ }^{119,120}$ The reduction of some GO nanosheets during operation will change the $d$-spacing, leading to unstable nanochannels, which is not suitable for precise separation. Besides, the size of the channels in water may also be changed due to the operation pressure. ${ }^{121,122}$

Fourthly, as far as we know, the effects of physical properties such as surface wrinkles and lateral width of GO nanosheets on the stability of a GO membrane in an aqueous environment are rarely reported. ${ }^{123,124}$ Correspondingly, facile and scalable methods for the fabrication of GO nanosheets with controllable surface wrinkles and lateral width also need to be developed.

In brief, more research studies are needed to endow the GO NF membrane with excellent stability while maintaining the high permeation flux and precise separation performance of the membrane.

\section{Conflicts of interest}

There are no conflicts to declare.

\section{Acknowledgements}

We thank the National Natural Science Foundation of China (No. 51903115 and 21878062) and the Nature Science Foundation of the Jiangxi Province (20192BAB203012).

\section{Notes and references}

1 Y. Zhang and T.-S. Chung, Curr. Opin. Chem. Eng., 2017, 16, 9-15.

2 S. J. Gao, D. Wang, W. X. Fang and J. Jin, Adv. Mater. Technol., 2020, 1901069, DOI: 10.1002/admt.201901069.

3 X. Q. Cheng, Z. X. Wang, X. Jiang, T. X. Li, C. H. Lau, Z. H. Guo, J. Ma and L. Shao, Prog. Mater. Sci., 2018, 92, 258-283.

4 H. Malmir, R. Epsztein, M. Elimelech and A. Haji-Akbari, Matter, 2020, 2, 735-750.

5 S. Homaeigohar and M. Elbahri, NPG Asia Mater., 2017, 9, e427.

6 Z. Wang, H.-C. Yang, F. He, S. Peng, Y. Li, L. Shao and S. B. Darling, Matter, 2019, 1, 115-155.
7 Y. Zhang, X. Cheng, X. Jiang, J. J. Urban, C. H. Lau, S. Liu and L. Shao, Mater. Today, 2020, DOI: 10.1016/j.mattod. 2020.02.002.

8 H. Sun, Y. Du, C. Gao, J. Long, S. Li and L. Shao, J. Membr. Sci., 2020, 604, 118071.

9 Y. Zhang, J. Ma and L. Shao, J. Mater. Chem. A, 2020, 8, 5078-5085.

10 X. S. Peng, J. Jin, Y. Nakamura, T. Ohno and I. Ichinose, Nat. Nanotechnol., 2009, 4, 353-357.

11 Z. P. Smith and B. D. Freeman, Angew. Chem., Int. Ed., 2014, 53, 10286-10288.

12 R. K. Joshi, S. Alwarappan, M. Yoshimura, V. Sahajwalla and Y. Nishina, Appl. Mater. Today, 2015, 1, 1-12.

13 K. Goh, H. E. Karahan, L. Wei, T.-H. Bae, A. G. Fane, R. Wang and Y. Chen, Carbon, 2016, 109, 694-710.

14 D. An, L. Yang, T.-J. Wang and B. Liu, Ind. Eng. Chem. Res., 2016, 55, 4803-4810.

15 Y. You, V. Sahajwalla, M. Yoshimura and R. K. Joshi, Nanoscale, 2016, 8, 117-119.

16 M. Fathizadeh, W. L. Xu, F. Zhou, Y. Yoon and M. Yu, Adv. Mater. Interfaces, 2017, 4, 1600918.

17 K. G. Zhou, K. S. Vasu, C. T. Cherian, M. Neek-Amal, J. C. Zhang, H. Ghorbanfekr-Kalashami, K. Huang, O. P. Marshall, V. G. Kravets, J. Abraham, Y. Su, A. N. Grigorenko, A. Pratt, A. K. Geim, F. M. Peeters, K. S. Novoselov and R. R. Nair, Nature, 2018, 559, 236.

18 L. Ries, E. Petit, T. Michel, C. C. Diogo, C. Gervais, C. Salameh, M. Bechelany, S. Balme, P. Miele, N. Onofrio and D. Voiry, Nat. Mater., 2019, 18, 1112-1117.

19 A. Akbari, B. V. Cunning, S. R. Joshi, C. Wang, D. C. Camacho-Mojica, S. Chatterjee, V. Modepalli, C. Cahoon, C. W. Bielawski, P. Bakharev, G.-H. Kim and R. S. Ruoff, Matter, 2020, 2, 1198-1206.

20 C. Chen, Q.-H. Yang, Y. Yang, W. Lv, Y. Wen, P.-X. Hou, M. Wang and H.-M. Cheng, Adv. Mater., 2009, 21, 3007-3011.

21 J. J. Shao, W. Lv and Q. H. Yang, Adv. Mater., 2014, 26, 5586-5612.

22 A. Akbari, P. Sheath, S. T. Martin, D. B. Shinde, M. Shaibani, P. C. Banerjee, R. Tkacz, D. Bhattacharyya and M. Majumder, Nat. Commun., 2016, 7, 10891.

23 J. W. Burress, S. Gadipelli, J. Ford, J. M. Simmons, W. Zhou and T. Yildirim, Angew. Chem., Int. Ed., 2010, 49, 8902-8904.

24 Y. H. Cho, H. W. Kim, H. D. Lee, J. E. Shin, B. M. Yoo and H. B. Park, J. Membr. Sci., 2017, 544, 425-435.

25 L. Chen, G. Shi, J. Shen, B. Peng, B. Zhang, Y. Wang, F. Bian, J. Wang, D. Li, Z. Qian, G. Xu, G. Liu, J. Zeng, L. Zhang, Y. Yang, G. Zhou, M. Wu, W. Jin, J. Li and H. Fang, Nature, 2017, 550, 380-383.

26 X. Chen, M. Qiu, H. Ding, K. Fu and Y. Fan, Nanoscale, 2016, 8, 5696-5705.

27 L. Liu, Y. Zhou, J. Xue and H. Wang, AIChE J., 2019, 65, 16699.

28 D. W. Boukhvalov, M. I. Katsnelson and Y. W. Son, Nano Lett., 2013, 13, 3930-3935.

29 H. Huang, Z. Song, N. Wei, L. Shi, Y. Mao, Y. Ying, L. Sun, Z. Xu and X. Peng, Nat. Commun., 2013, 4, 2979. 
30 Q. Yang, Y. Su, C. Chi, C. T. Cherian, K. Huang, V. G. Kravets, F. C. Wang, J. C. Zhang, A. Pratt, A. N. Grigorenko, F. Guinea, A. K. Geim and R. R. Nair, Nat. Mater., 2017, 16, 1198-1202.

31 Y. Li, W. Zhao, M. Weyland, S. Yuan, Y. Xia, H. Liu, M. Jian, J. Yang, C. D. Easton, C. Selomulya and X. Zhang, Environ. Sci. Technol., 2019, 53, 8314-8323.

32 P. Sun, M. Zhu, K. Wang, M. Zhong, J. Wei, D. Wu, Z. Xu and H. Zhu, ACS Nano, 2013, 7, 428-437.

33 P. Sun, F. Zheng, M. Zhu, Z. Song, K. Wang, M. Zhong, D. $\mathrm{Wu}, \mathrm{R}$. B. Little, Z. Xu and H. Zhu, ACS Nano, 2014, 8, 850-859.

34 J. Abraham, K. S. Vasu, C. D. Williams, K. Gopinadhan, Y. Su, C. T. Cherian, J. Dix, E. Prestat, S. J. Haigh, I. V. Grigorieva, P. Carbone, A. K. Geim and R. R. Nair, Nat. Nanotechnol., 2017, 12, 546.

35 S. Zheng, Q. Tu, J. J. Urban, S. Li and B. Mi, ACS Nano, 2017, 11, 6440-6450.

36 Z. Wang, Q. Tu, S. Zheng, J. J. Urban, S. Li and B. Mi, Nano Lett., 2017, 17, 7289-7298.

37 C. N. Yeh, K. Raidongia, J. Shao, Q. H. Yang and J. Huang, Nat. Chem., 2014, 7, 166-170.

38 Y.-H. Xi, Z. Liu, Q.-C. Liao, R. Xie, X.-J. Ju, W. Wang, Y. Faraj and L.-Y. Chu, Ind. Eng. Chem. Res., 2018, 57, 9439-9447.

39 Y. Mo, X. Zhao and Y.-X. Shen, Desalination, 2016, 399, 40-46.

40 S. Sun, C. Wang, M. Chen and M. Li, Chem. Phys. Lett., 2013, 561-562, 166-169.

41 M. Zhang, J. Sun, Y. Mao, G. Liu and W. Jin, J. Membr. Sci., 2019, 574, 196-204.

42 N. F. D. Aba, J. Y. Chong, B. Wang, C. Mattevi and K. Li, J. Membr. Sci., 2015, 484, 87-94.

43 S. Park, K. S. Lee, G. Bozoklu, W. Cai, S. T. Nguyen and R. S. Ruoff, ACS Nano, 2008, 2, 572-578.

44 Y. Liu, B. Xie and Z. Xu, J. Mater. Chem., 2011, 21, 6707.

45 B. Feng, K. Xu and A. Huang, Desalination, 2016, 394, 123-130.

46 K. H. Thebo, X. Qian, Q. Zhang, L. Chen, H. M. Cheng and W. Ren, Nat. Commun., 2018, 9, 1486.

47 S. Wan, Y. Chen, Y. Wang, G. Li, G. Wang, L. Liu, J. Zhang, Y. Liu, Z. Xu, A. P. Tomsia, L. Jiang and Q. Cheng, Matter, 2019, 1, 389-401.

48 M. Hu and B. Mi, Environ. Sci. Technol., 2013, 47, 3715-3723.

49 W.-S. Hung, C.-H. Tsou, M. De Guzman, Q.-F. An, Y.-L. Liu, Y.-M. Zhang, C.-C. Hu, K.-R. Lee and J.-Y. Lai, Chem. Mater., 2014, 26, 2983-2990.

50 Y. Zhang, S. Zhang and T. S. Chung, Environ. Sci. Technol., 2015, 49, 10235-10242.

51 Y. T. Nam, J. Choi, K. M. Kang, D. W. Kim and H. T. Jung, ACS Appl. Mater. Interfaces, 2016, 8, 27376-27382.

52 P. Zhang, J.-L. Gong, G.-M. Zeng, C.-H. Deng, H.-C. Yang, H.-Y. Liu and S.-Y. Huan, Chem. Eng. J., 2017, 322, 657-666.

53 S. Kim, X. Lin, R. Ou, H. Liu, X. Zhang, G. P. Simon, C. D. Easton and H. Wang, J. Mater. Chem. A, 2017, 5, 1533-1540.
54 M.-Y. Lim, Y.-S. Choi, J. Kim, K. Kim, H. Shin, J.-J. Kim, D. M. Shin and J.-C. Lee, J. Membr. Sci., 2017, 521, 1-9.

55 N. Meng, W. Zhao, E. Shamsaei, G. Wang, X. Zeng, X. Lin, T. Xu, H. Wang and X. Zhang, J. Membr. Sci., 2018, 548, 363-371.

56 H. Lin, S. Dangwal, R. Liu, S.-J. Kim, Y. Li and J. Zhu, J. Membr. Sci., 2018, 563, 336-344.

57 P. S. Parsamehr, M. Zahed, M. A. Tofighy, T. Mohammadi and M. Rezakazemi, Desalination, 2019, 468, 114079.

58 L. Zhang, A. Ghaffar, X. Zhu and B. Chen, Environ. Sci. Technol., 2019, 53, 10398-10407.

59 V. Kandjou, A. M. Perez-Mas, B. Acevedo, M. Hernaez, A. G. Mayes and S. Melendi-Espina, J. Hazard. Mater., 2019, 380, 120840.

60 M.-L. Liu, J.-L. Guo, S. Japip, T.-Z. Jia, D.-D. Shao, S. Zhang, W.-J. Li, J. Wang, X.-L. Cao and S.-P. Sun, J. Mater. Chem. A, 2019, 7, 3170-3178.

61 Y. Xu, G. Peng, J. Liao, J. Shen and C. Gao, J. Membr. Sci., 2020, 601, 117727.

62 H. Lin, Y. Li and J. Zhu, J. Membr. Sci., 2020, 598, 117789.

63 M. Zhang, Y. Mao, G. Liu, G. Liu, Y. Fan and W. Jin, Angew. Chem., Int. Ed., 2020, 59, 1689-1695.

64 L. Dong, M. Li, S. Zhang, X. Si, Y. Bai and C. Zhang, Desalination, 2020, 476, 114227.

65 F. Pan, Y. Li, Y. Song, M. Wang, Y. Zhang, H. Yang, H. Wang and Z. Jiang, J. Membr. Sci., 2020, 595, 117486.

66 R. Yi, R. Yang, R. Yu, J. Lan, J. Chen, Z. Wang, L. Chen and M. Wu, RSC Adv., 2019, 9, 40397-40403.

67 E. Halakoo and X. Feng, Chem. Eng. Sci., 2020, 216, 115488.

68 J. Ye, B. Zhang, Y. Gu, M. Yu, D. Wang, J. Wu and J. Li, ACS Appl. Nano Mater., 2019, 2, 6611-6621.

69 W. Yu, T. Yu and N. Graham, 2D Mater., 2017, 4, 045006.

70 T. Liu, B. Yang, N. Graham, W. Yu and K. Sun, J. Membr. Sci., 2017, 542, 31-40.

71 A. Ghaffar, L. Zhang, X. Zhu and B. Chen, Environ. Sci.: Nano, 2019, 6, 904-915.

72 T. Liu, L. Tian, N. Graham, B. Yang, W. Yu and K. Sun, Environ. Sci. Technol., 2019, 53, 11949-11959.

73 L. Nie, K. Goh, Y. Wang, J. Lee, Y. Huang, H. E. Karahan, K. Zhou, M. D. Guiver and T.-H. Bae, Sci. Adv., 2020, 6, eaaz9184.

74 Y. H. Xi, J. Q. Hu, Z. Liu, R. Xie, X. J. Ju, W. Wang and L. Y. Chu, ACS Appl. Mater. Interfaces, 2016, 8, 15557-15566.

75 H. Liu, H. Wang and X. Zhang, Adv. Mater., 2015, 27, 249-254.

76 L. Huang, J. Chen, T. Gao, M. Zhang, Y. Li, L. Dai, L. Qu and G. Shi, Adv. Mater., 2016, 28, 8669-8674.

77 A. Morelos-Gomez, R. Cruz-Silva, H. Muramatsu, J. OrtizMedina, T. Araki, T. Fukuyo, S. Tejima, K. Takeuchi, T. Hayashi, M. Terrones and M. Endo, Nat. Nanotechnol., 2017, 12, 1083-1088.

78 Q. Zhang, X. Qian, K. H. Thebo, H.-M. Cheng and W. Ren, Sci. Bull., 2018, 63, 788-794.

79 K. M. Cho, H. J. Lee, Y. T. Nam, Y. J. Kim, C. Kim, K. M. Kang, C. A. Ruiz Torres, D. W. Kim and H. T. Jung, ACS Appl. Mater. Interfaces, 2019, 11, 27004-27010. 
80 Z. Zhao, S. Ni, X. Su, Y. Gao and X. Sun, ACS Sustainable Chem. Eng., 2019, 7, 14874-14882.

81 Y. Li, S. Yuan, Y. Xia, W. Zhao, C. D. Easton, C. Selomulya and X. Zhang, J. Membr. Sci., 2020, 601, 117900.

82 J. Ran, C. Chu, T. Pan, L. Ding, P. Cui, C.-F. Fu, C.-L. Zhang and T. Xu, J. Mater. Chem. A, 2019, 7, 8085-8091.

83 K. Goh, W. Jiang, H. E. Karahan, S. Zhai, L. Wei, D. Yu, A. G. Fane, R. Wang and Y. Chen, Adv. Funct. Mater., 2015, 25, 7348-7359.

84 M. Musielak, A. Gagor, B. Zawisza, E. Talik and R. Sitko, ACS Appl. Mater. Interfaces, 2019, 11, 28582-28590.

85 Y. Yang, X. Yang, L. Liang, Y. Gao, H. Cheng, X. Li, M. Zou, R. Ma, Q. Yuan and X. Duan, Science, 2019, 364, 1057-1062.

86 M. Zhang, K. Guan, J. Shen, G. Liu, Y. Fan and W. Jin, AIChE J., 2017, 63, 5054-5063.

87 W. Liu, D. Wang, R. A. Soomro, F. Fu, N. Qiao, Y. Yu, R. Wang and B. Xu, J. Membr. Sci., 2019, 591, 117323.

88 M. Kunimatsu, K. Nakagawa, T. Yoshioka, T. Shintani, T. Yasui, E. Kamio, S. C. E. Tsang, J. Li and H. Matsuyama, J. Membr. Sci., 2020, 595, 117598.

89 J. Ma, X. Tang, Y. He, Y. Fan, J. Chen and H. Yu, Desalination, 2020, 480, 114328.

90 H. Lin, N. Mehra, Y. Li and J. Zhu, J. Membr. Sci., 2020, 593, 117401.

91 T. Liu, X. Liu, N. Graham, W. Yu and K. Sun, J. Membr. Sci., 2020, 593, 117431.

92 J. Li, M. Hu, H. Pei, X. Ma, F. Yan, D. S. Dlamini, Z. Cui, B. He, J. Li and H. Matsuyama, J. Membr. Sci., 2020, 595, 117547.

93 T. Wang, J. Lu, L. Mao and Z. Wang, J. Membr. Sci., 2016, 515, 125-133.

94 C.-M. Kim, S. Hong, R. Li, I. S. Kim and P. Wang, ACS Sustainable Chem. Eng., 2019, 7, 7252-7259.

95 K. Huang, G. Liu, J. Shen, Z. Chu, H. Zhou, X. Gu, W. Jin and N. Xu, Adv. Funct. Mater., 2015, 25, 5809-5815.

96 G. Wei, J. Dong, J. Bai, Y. Zhao and Y. Li, Environ. Sci. Technol., 2019, 53, 11896-11903.

97 L. Chen, N. Li, Z. Y. Wen, L. Zhang, Q. Chen, L. N. Chen, P. C. Si, J. K. Feng, Y. H. Li, J. Lou and L. J. Ci, Chem. Eng. J., 2018, 347, 12-18.

98 W. Wu, J. Su, M. Jia, W. Zhong, Z. Li and W. Li, J. Mater. Chem. A, 2019, 7, 13007-13011.

99 Y. Lou, G. Liu, S. Liu, J. Shen and W. Jin, Appl. Surf. Sci., 2014, 307, 631-637.

100 F. He, M. Han, J. Zhang, Z. Wang, X. Wu, Y. Zhou, L. Jiang, S. Peng and Y. Li, Nano Energy, 2020, 71, 104650.

101 Z. Wang, S. Ji, F. He, M. Cao, S. Peng and Y. Li, J. Mater. Chem. A, 2018, 6, 3391-3396.

102 Y. Xu, D. Guo, T. Li, Y. Xiao, L. Shen, R. Li, Y. Jiao and H. Lin, J. Colloid Interface Sci., 2020, 565, 23-34.
103 Z. Wang, M. Han, J. Zhang, F. He, Z. Xu, S. Ji, S. Peng and Y. Li, Chem. Eng. J., 2019, 360, 299-312.

104 J. Zhang, L. Zhang, J. Zhao, W. Qu and Z. Wang, Green Chem., 2019, 21, 5080-5089.

105 Z. Wang, S. Ji, J. Zhang, Q. Liu, F. He, S. Peng and Y. Li, J. Mater. Chem. A, 2018, 6, 13959-13967.

106 D. Guo, Y. Xiao, T. Li, Q. Zhou, L. Shen, R. Li, Y. Xu and H. Lin, J. Colloid Interface Sci., 2020, 560, 273-283.

107 Z. Wang, X. Yang, Z. Cheng, Y. Liu, L. Shao and L. Jiang, Mater. Horiz., 2017, 4, 701-708.

108 J. Zhang, J. Zhao, W. Qu and Z. Wang, Mater. Chem. Front., 2019, 3, 1341-1348.

109 Z. Wang, M. Han, J. Zhang, F. He, S. Peng and Y. Li, J. Membr. Sci., 2020, 593, 117383.

110 X. Yang, P. Sun, H. Zhang, Z. Xia, R. Z. Waldman, A. U. Mane, J. W. Elam, L. Shao and S. B. Darling, Adv. Funct. Mater., 2020, 1910062, DOI: 10.1002/adfm.201910062.

111 L. Yan, X. Yang, J. Long, X. Cheng, D. Pan, Y. Huang and L. Shao, Chem. Commun., 2020, 56, 478-481.

112 X. Yang, L. Yan, F. Ran, Y. Huang, D. Pan, Y. Bai and L. Shao, J. Membr. Sci., 2020, 597, 117753.

113 K. Xu, B. Feng, C. Zhou and A. Huang, Chem. Eng. Sci., 2016, 146, 159-165.

114 C. Wang, Z. Li, J. Chen, Y. Yin and H. Wu, Appl. Surf. Sci., 2018, 427, 1092-1098.

115 Y. Qin, H. Liu, Y. Liu, M. Chen, K. Chen, Y. Huang and C. Xiao, J. Membr. Sci., 2020, 604, 118064.

116 J. Y. Chong, N. F. Aba, B. Wang, C. Mattevi and K. Li, Sci. Rep., 2015, 5, 15799.

117 B. McVerry, M. Anderson, N. He, H. Kweon, C. Ji, S. Xue, E. Rao, C. Lee, C. W. Lin, D. Chen, D. Jun, G. Sant and R. B. Kaner, Nano Lett., 2019, 19, 5036-5043.

118 S. Xue, C. Ji, M. D. Kowal, J. C. Molas, C. W. Lin, B. T. McVerry, C. L. Turner, W. H. Mak, M. Anderson, M. Muni, E. M. V. Hoek, Z. L. Xu and R. B. Kaner, Nano Lett., 2020, 20(4), 2209-2218.

119 S. Kim, S. Zhou, Y. Hu, M. Acik, Y. J. Chabal, C. Berger, W. de Heer, A. Bongiorno and E. Riedo, Nat. Mater., 2012, 11, 544-549.

120 P. V. Kumar, N. M. Bardhan, S. Tongay, J. Wu, A. M. Belcher and J. C. Grossman, Nat. Chem., 2014, 6, 151-158.

121 J. Y. Chong, B. Wang, C. Mattevi and K. Li, J. Membr. Sci., 2018, 549, 385-392.

122 W. Li, W. Wu and Z. Li, ACS Nano, 2018, 12, 9309-9317.

123 Y. Wei, Y. Zhang, X. Gao, Y. Yuan, B. Su and C. Gao, Carbon, 2016, 108, 568-575.

124 S. Remanan, N. Padmavathy, S. Ghosh, S. Mondal, S. Bose and N. C. Das, Sep. Purif. Rev., 2020, 1-21, DOI: 10.1080/ 15422119.2020.1725048. 